\title{
Aspects of magnetosphere-ionosphere coupling in sawtooth substorms: a case study
}

\author{
P. E. Sandholt ${ }^{1}$ and C. J. Farrugia ${ }^{2}$ \\ ${ }^{1}$ Department of Physics, University of Oslo, Oslo, Norway \\ ${ }^{2}$ Space Science Center, University of New Hampshire, Durham, USA \\ Correspondence to: P. E. Sandholt (p.e.sandholt@fys.uio.no)
}

Received: 26 November 2013 - Revised: 10 September 2014 - Accepted: 15 September 2014 - Published: 20 October 2014

\begin{abstract}
In a case study we report on repetitive substorm activity during storm time which was excited during Earth passage of an interplanetary coronal mass ejection (ICME) on 18 August 2003. Applying a combination of magnetosphere and ground observations during a favourable multispacecraft configuration in the plasma sheet (GOES-10 at geostationary altitude) and in the tail lobes (Geotail and Cluster-1), we monitor the temporal-spatial evolution of basic elements of the substorm current system. Emphasis is placed on activations of the large-scale substorm current wedge (SCW), spanning the 21:00-03:00 MLT sector of the near-Earth plasma sheet (GOES-10 data during the interval 06:00-12:00 UT), and magnetic perturbations in the tail lobes in relation to ground observations of auroral electrojets and convection in the polar cap ionosphere. The joint ground-satellite observations are interpreted in terms of sequential intensifications and expansions of the outer and inner current loops of the SCW and their respective associations with the westward electrojet centred near midnight (24:00 MLT) and the eastward electrojet observed at 14:0015:00 MLT. Combined magnetic field observations across the tail lobe from Cluster and Geotail allow us to make estimates of enhancements of the cross-polar-cap potential (CPCP) amounting to $\approx 30-60 \mathrm{kV}$ (lower limits), corresponding to monotonic increases of the PCN index by 1.5 to $3 \mathrm{mV} \mathrm{m}^{-1}$ from inductive electric field coupling in the magnetosphereionosphere (M-I) system during the initial transient phase of the substorm expansion.
\end{abstract}

Keywords. Magnetospheric physics (magnetosphereionosphere interactions)

\section{Introduction}

Depending on solar wind conditions, magnetospheric substorms may appear in different variants. Such are the "classical" isolated substorms (with fully developed growthexpansion-recovery phases; see Akasofu, 1964); double (or multiple)-onset substorms (major, full-scale onset preceded by pseudo-breakup; see e.g. Koskinen et al., 1993; Pulkkinen et al., 1998, and Kullen et al., 2009); and repetitive, large substorms during storm times, sometimes referred to as sawtooth events (Henderson et al., 2006). A standard definition of "classical" substorms includes typical signatures such as (i) a plasma injection at geostationary altitude $\left(6.6 R_{\mathrm{E}}\right)$, (ii) a dipolarization of the inner-magnetotail magnetic field, and (iii) a rapid enhancement and poleward expansion (Friedrich et al., 2001) of the westward electrojet (WEJ) in the auroral ionosphere (Pulkkinen et al., 2007). Pseudo-breakups consist of a brief brightening event with small spatial extent. In such cases, the magnetospheric source, i.e. the current disruption (CD) process in the near-Earth plasma sheet (PS), does not expand into a global, "classical" substorm (Nakamura et al., 1992; Kozelova et al., 1992). Thus this variant has been described as the smallest type of a substorm (e.g. Nakamura et al., 1994; Aikio et al., 1999). According to Lui (2000) "a substorm follows when the global condition is favourable, so that a local activity may trigger a system-wide activity which we call a substorm." This scenario is consistent with the description of Cowley (1992), who concluded that substorms are basically a two-step process, consisting of dipolarization near the inner edge of the plasma sheet $\left(\sim 5-15 R_{\mathrm{E}}\right)$ followed by near-Earth $\left(25-30 R_{\mathrm{E}}\right)$ tail reconnection.

In this study we document the detailed temporal structure of the magnetic field events (magnetic field dipolarizations) 
appearing in the near-Earth PS, at geosynchronous altitude, and in the tail lobes, as well as central features of the associated magnetosphere-ionosphere (M-I) coupling during sawtooth substorms (whose characteristic phenomena are given below). The observations will be discussed in the context of a model of M-I coupling consisting of three basic elements: (i) activation of the substorm current wedge (SCW; see McPherron et al., 1973) with re-routing of part of the cross-tail current (CTC) via Birkeland currents to the WEJ in the ionosphere (auroral oval around midnight); (ii) a system of Bostrøm type II current sheets (Bostrøm, 1964) connecting the partial ring current (PRC)-PS inner boundary and the auroral oval south, maximizing at dusk and dawn; and (iii) coupling of an enhanced electric field from the tail lobes ( $E_{\mathrm{TL}}$ enhancement as a result of magnetotail reconnection; see e.g. Sauvaud et al., 2012) to the polar cap (PC) ionosphere, giving rise to $\mathrm{PC}$ convection enhancements.

Current system (i) (SCW) may be activated by a current disruption $(\mathrm{CD})$ in the near-Earth $\left(7-10 R_{\mathrm{E}}\right)$ plasma sheet (Lui, 1991). Current system (ii), i.e., Bostrøm type II, can be activated by plasma inflow from the $\mathrm{CD}$ region (Lui and Murphree, 1998), resulting in a plasma injection dynamo $(\boldsymbol{E} \cdot \boldsymbol{J}<0)$ associated with plasma flow braking at the inner edge of the PS (Birn and Hesse, 2013). M-I coupling channel (iii) from the tail lobe to the polar cap is activated by the $E_{\mathrm{TL}}$ enhancement associated with reconnection of tail lobe flux at the near-Earth neutral line (NENL), as recently documented by Sauvaud et al. (2012). At present there are still unresolved questions on the temporal evolution of these M-I coupling processes taking place during substorms (see e.g. Sergeev et al., 2012; Sauvaud et al., 2012; Akasofu, 2013).

In this paper we combine ground-satellite data to shed light on this issue. The data we selected for this study were obtained during a $7 \mathrm{~h}$ long interval of continuously high solar wind forcing (interplanetary coronal mass ejection (ICME) passage at Earth on 18 August 2003) which gave rise to three consecutive sawtooth substorms recurring at $2 \mathrm{~h}$ and 15 min intervals. Process (i) was monitored by GOES-10 observations of magnetic field dipolarizations in the 20:0003:00 MLT (magnetic local time) sector in combination with WEJ activity inferred from Alaska chain magnetometer data in the 19:00-01:00 MLT sector. Activation of coupling channel (ii) is monitored by the associated eastward electrojet (EEJ) current in the postnoon-to-dusk sector by IMAGE chain (Scandinavia-Finland) magnetograms. Coupling channel (iii) is followed by the PCN index (Troshichev et al., 2000). Thus, an important aspect of this study is the excitation and temporal evolution of PC convection during the multi-phase evolution of the three consecutive sawtooth substorms appearing in our selected interval. The roles of inductive and potential fields in these M-I coupling events is a topic of current investigation (see e.g. Katus et al., 2013) which we will address in the present case study.

Sawtooth substorms, which may occur primarily during geomagnetic storms (see Noah and Burke, 2014), are characterized by (i) magnetic field stretching accompanied by a gradual decrease of the energetic particle flux at geosynchronous altitude, followed by (ii) magnetic field dipolar/ization and rapid increase of the energetic particle flux (particle injection in the dusk-to-midnight sector), (iii) a localized auroral onset in the pre-midnight sector which occurs on the equatorward branch of a thinned double-oval configuration, (iv) auroral zone negative $H$ bays and middle- and lowlatitude positive $H$ bays, (v) Pi2 pulsations, and (vi) wide substorm-like current wedges (see Henderson et al., 2006, and references therein).

There has been some discussion on the peculiarities of sawtooth substorms (e.g. the repetition period between 2 and $4 \mathrm{~h}$; the abnormally large spatial extent; and only partial recovery of WEJ activity between events, as measured by the AL (WEJ index)), i.e. whether they represent a distinct class of magnetospheric activity or not. According to Pulkkinen et al. (2007), sawtooth events have auroral and inner magnetosphere characteristics that are quite similar to those found generally during storm-time activity. Hence they conclude that sawtooth events do not represent a specific class of activity. In this view, sawtooth events constitute rather a subset of large, recurrent substorms driven by long-lasting high solar wind forcing. According to Troshichev and Janzhura (2009), "the classical development of the substorm, put forward by Akasofu (1964) for isolated substorms, is not workable in the cases of sawtooth disturbances, when powerful solar wind energy pumping into the magnetosphere provides a permanent powerful aurora particle precipitation into the auroral zone." They find that the close relationship between particle injection at geostationary orbit and auroral onset documented in "classical substorms" is broken in the powerful sawtooth substorms. They note, however, that this "inconsistency" can be affected by the local time differences between the auroral brightening location (or the ground station that contributes to the "AL onset") and the location of the spacecraft that sees the injection. Related to this we note that, when we study $\mathrm{M}-\mathrm{I}$ coupling during sawtooth substorms, we combine observations from geostationary altitude (GEOS-10 satellite) and ground magnetic data (WEJ activity) from stations in Alaska. In our case the observations relating to the magnetospheric and ionospheric levels are separated by only $2 \mathrm{~h}$ in MLT. (In the interval we study, GOES and Alaska are moving with the Earth through the MLT sectors 21:00-03:00 and 19:0001:00, respectively, i.e. both cover $6 \mathrm{~h}$ of nightside MLTs.)

In a recent study we documented the activation of magnetospheric current systems (Bostrøm types I and II; see Bostrøm, 1964, 1967) with associated auroral electrojet events on both sides of the Harang reversal boundary at dusk during the ICME passage at Earth on 18 August 2003 substorms (Sandholt et al., 2014) (hereafter referred to as Paper 1). The WEJ was observed to expand repeatedly into the 17:00-18:00 MLT sector during substorm activations. These observations of dusk signatures are consistent with previous reports on the abnormally large MLT extent of sawtooth 
substorms (Henderson et al., 2006; Troshichev and Janzhura, 2009).

In the present study we find that three consecutive sawtooth events on this same day are double-onset substorms with a corresponding two-step M-I coupling sequence consisting of (i) an initial dipolarization with corresponding pseudo-breakup of the WEJ and weak PC convection (PCN, polar cap north index) response (see also Kullen et al., 2010), followed by (ii) a subsequent major onset of the WEJ and a major PC convection response. Each of these three twostep onsets are preceded by an interval of field stretching and gradual energetic particle decrease in the near-Earth PS, as expected for sawtooth events. The further implications that follow from these observations on the detailed evolution of $\mathrm{M}-\mathrm{I}$ coupling processes across the auroral oval and the polar cap during these sawtooth substorms will be discussed.

From the available data we obtain information on the chronology of the M-I coupling processes such as (i) the PS $\mathrm{CD}$ (dipolarization) events and activations of the substorm current wedge (SCW) from GOES-10 data and Alaska chain magnetometer data, (ii) plasma injections to the PRC (SYMH dips; see Paper 1), and (iii) the evolution of the tail lobe to polar cap coupling from the combination of Cluster-1 magnetic field perturbations and the PCN index. With this approach we want to investigate the possible role of inductive electric fields in M-I coupling during sawtooth substorms considering the spatial-temporal evolution of substorm current loops with auroral electrojet manifestations at midnight (Alaska chain) and near 15:00 MLT (IMAGE chain in the Svalbard-Scandinavia-Finland region).

\section{Conceptual model of M-I coupling}

As a background for the later discussion of the observations, in Fig. 1 we show a schematic illustration of M-I coupling channels via substorm current systems. Magnetospheric plasma flow features and associated current loops in the Northern Hemisphere are indicated. The different current loops consist of field-aligned currents and their closure currents (normal to the magnetic field) in the magnetosphere and the ionosphere. The Bostrøm type I loop (i.e. the outer loop of the substorm current wedge: SCW) is connected to an azimuthal ionospheric current (westward electrojet: WEJ). The Bostrøm type II loop is connected to a meridional (north-south) ionospheric current. The FACs (field-aligned currents) in the meridional loops consist of bipolar, eastwest-aligned current sheets. Both current loops are powered by plasma injection dynamos in the plasma sheet, where the $\boldsymbol{E}$ and $\boldsymbol{J}$ are oppositely directed $(\boldsymbol{E} \cdot \boldsymbol{J}<0)$, as indicated. Basic dynamic elements of the magnetosphere perspective are (i) large-scale disruptions of the cross-tail current (CTC) in the SCW and (ii) smaller-scale disruptions with associated FACs (wedgelets) connecting to earthward-propagating bursty bulk flows (BBFs). The corresponding ionospheric

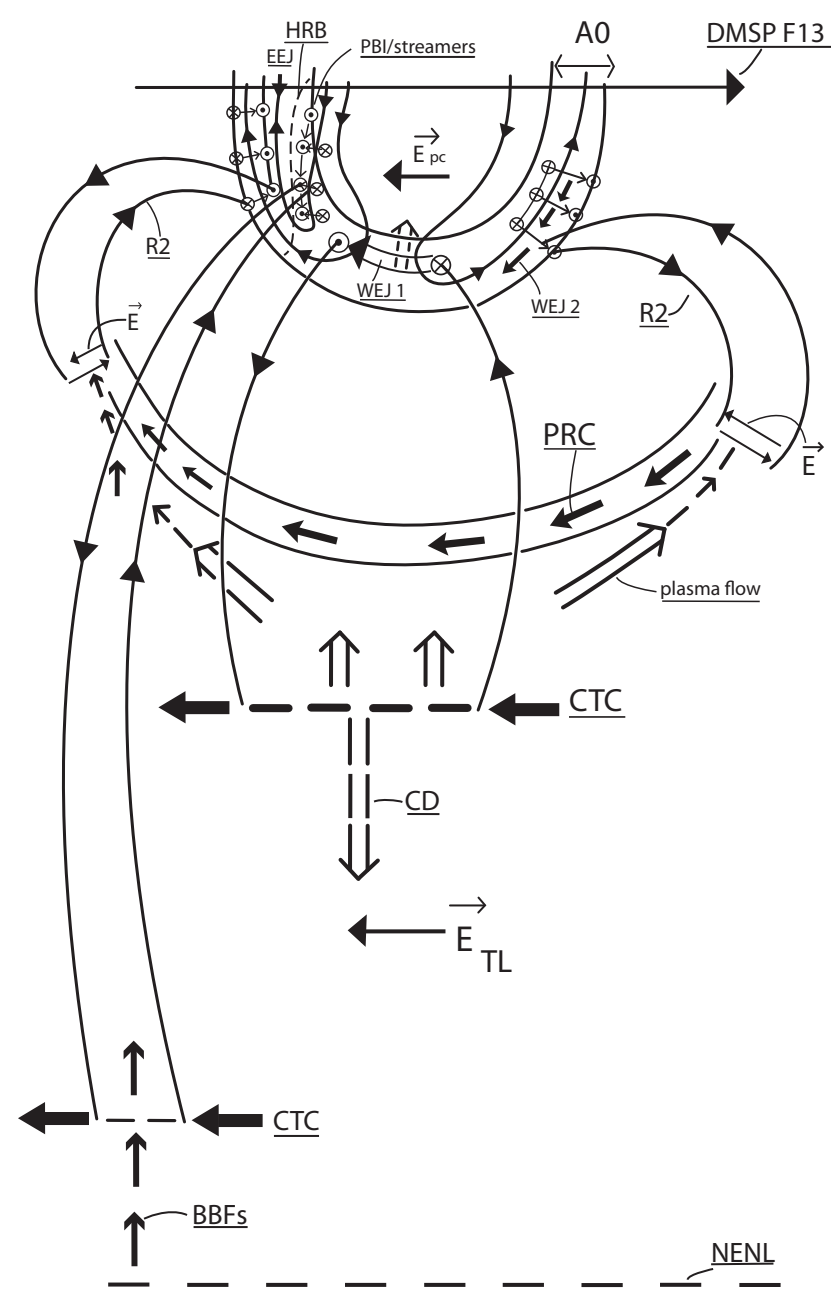

Figure 1. Schematic illustration showing four different channels of M-I coupling operating during substorm activity: (i) auroral oval around midnight (westward electrojet: WEJ) to near-Earth plasma sheet (Bostrøm type I: large-scale SCW), (ii) auroral oval south at dawn/dusk to PS-PRC boundary (Bostrøm type II), (iii) auroral oval north at dusk to midtail PS (Bostrøm type I: current wedgelet), and (iv) electric field (potential) coupling along open field lines between the polar cap ionosphere and the lobes of the magnetotail. See text for details.

connections in the north and south branches of the auroral oval, respectively, on the dusk/dawn sides of the SCW are shown. Current disruption (CD) events originating in the near-Earth PS and propagating tailward are marked. Associated magnetic perturbations and electric fields in the tail lobes $\left(E_{\mathrm{TL}}\right)$ are observed (estimated) in this article. They are coupled to the polar cap ionosphere $\left(\boldsymbol{E}_{\mathrm{PC}}\right)$ causing antisunward, cross-polar-cap convection, as indicated. Thus, the figure illustrates four channels of M-I coupling, as described in the caption. In this paper we study three of these coupling channels: (i) the outer loop of the SCW: auroral oval around midnight (WEJ) to the near-Earth PS (Bostrøm type I: large-scale SCW; McPherron et al., 1973), (ii) the 
inner loop of the SCW: auroral oval in the postnoon-to-dusk sector (EEJ) to the near-Earth plasma-sheet-partial-ring current (PRC: Bostrøm type II), and (iii) electric field (potential) coupling along open field lines between the tail lobes and the polar cap. With our M-I data sets we are monitoring the temporal-spatial evolution of this system during the repetitive sawtooth substorm events.

The figure also marks the observation geometry at dusk where we combine ground magnetic observations by the IMAGE chain in the Svalbard-Scandinavia-Finland region and DMSP F13 data. A central feature of this sector is the boundary between the EEJ and WEJ in the evening to premidnight sector - also delimiting the southern and northern branches of the aurora, marked by a dashed curved line - is the Harang reversal boundary (HRB). The northern auroral branch in this sector (HR-N) is characterized by equatorward-moving auroral forms (streamers) which are coupled to earthwardmoving plasma-depleted flux tubes (Chen and Wolf, 1993) and associated bursty bulk flows (BBFs) in the PS (Sergeev et al., 2004, 2012; Sandholt et al., 2014). During "classical" substorms the HR is typically found in the 19:00-24:00 MLT sector (Nielsen and Greenwald, 1979). However, during the type of persistent strong solar wind forcing conditions we study (18 August 2003), the WEJ and the Harang reversal repeatedly expanded into the 17:00-18:00 MLT sector, as documented in a recent ground-satellite DMSP F13 conjunction study (Paper 1). The dusk-dawn polar passes of the DMSP F13 satellite used to identify the HRB in that study have been indicated in the figure.

In the conceptual model indicated in Fig. 1, we extend the standard two-loop model of the SCW (Sergeev et al., 2014) when we specify the inner loop connecting the partial ring current (PRC) and the ionosphere (EEJ in auroral oval south regime) via the Bostrøm type II current system. This is essential for a proper description of M-I coupling during substorm activity.

As we shall see below, Geotail and Cluster data from the tail lobes and the combination of these observations with the GOES-10 monitoring of the substorm current wedge (SCW) at geostationary altitude allow us to discuss the substorm dynamics in a broad $\mathrm{M}-\mathrm{I}$ context, i.e. $\mathrm{M}-\mathrm{I}$ coupling involving the outer and inner loops of the SCW and inductive electric field coupling from the tail lobes to the polar cap ionosphere.

\section{Data description}

\subsection{Interplanetary data: $\mathrm{ACE}$}

Figure 2 shows IP (interplanetary) magnetic field and plasma data from the ACE satellite on 18 August 2003. The panels show, from top to bottom, the proton density, bulk speed, temperature (in red: expected proton temperature after Lopez and Freeman, 1986), the dynamic pressure, the GSM components of the magnetic field and the total field, the Kan-Lee

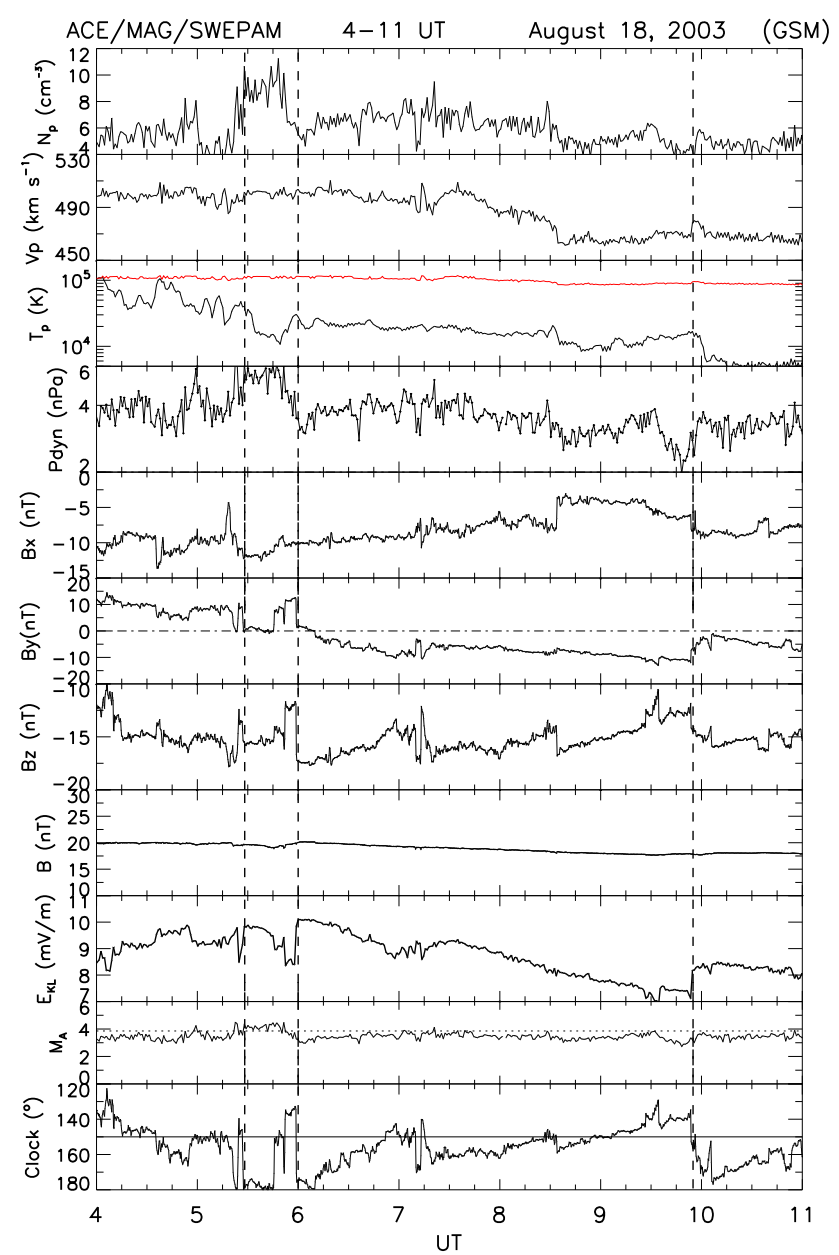

Figure 2. Interplanetary data from the ACE satellite during the interval 04:00-11:00 UT. Panels from top to bottom show proton density $\left(N_{\mathrm{p}} ; \mathrm{cm}^{-3}\right)$; bulk speed $\left(V_{\mathrm{p}} ; \mathrm{km} \mathrm{s}^{-1}\right)$; proton temperature $T_{\mathrm{p}}$ (K; in red the expected temperature after Lopez and Freeman, 1986); dynamic pressure $P_{\text {dyn }}(\mathrm{nPa})$, magnetic field components $B_{x}, B_{y}$, and $B_{z}$ in GSM coordinates; the field strength $B(\mathrm{nT})$; the Kan-Lee merging electric field, $E_{\mathrm{KL}}\left(\mathrm{mV} \mathrm{m}^{-1}\right)$; the Alfvén Mach number, $M_{\mathrm{A}}$; and the clock angle of the magnetic field $\left(^{\circ}\right)$. The three most geoeffective (see $E_{\mathrm{KL}}$ ) magnetic field directional discontinuities (DDs) are marked by vertical dashed guidelines.

merging electric field $E_{\mathrm{KL}}$ (Kan and Lee, 1979), and the clock angle, i.e. the polar angle in the GSM $Y-Z$ plane. $E_{\mathrm{KL}}=V B_{T} \sin ^{2}(\theta / 2)$, where $V$ is the solar wind bulk speed, $B_{T}=\left(B_{y}^{2}+B_{z}^{2}\right)^{1 / 2}$, and $\theta$ is the clock angle. ACE was located at $(228,-34,13) R_{\mathrm{E}}$.

The data were acquired during the passage at Earth of a long-duration ICME lasting from 01:00 UT on 18 August until 15:00 UT on 19 August (Richardson and Cane, 2010). Three outstanding magnetic field direction discontinuities, and associated dynamic pressure changes, are marked by vertical guidelines. The transients at 06:00 and 09:55 UT are expected to be geoeffective events (see abrupt $E_{\mathrm{KL}}$ increases), i.e. giving rise to $\mathrm{PC}$ convection enhancements. Noteworthy 
are also (i) the wide range of variation in the dynamic pressure $\left(P_{\mathrm{dyn}}\right)$; (ii) the magnetic field vector, with its clock angle spanning the range $180-130^{\circ}\left(B_{y}<0\right.$ after 06:10 UT; $B_{z}=-10$ to $-17 \mathrm{nT}$ ); and, most importantly, (iii) the high values of the merging electric field $\left(E_{\mathrm{KL}}=7-10 \mathrm{mV} \mathrm{m}^{-1}\right)$ and the low Alfvén Mach number (2-5) compared to typical solar wind values $(\sim 8-10)$. The bulk speed was $500 \mathrm{~km} \mathrm{~s}^{-1}$ until 07:30 UT before it decreased to $470 \mathrm{~km} \mathrm{~s}^{-1}$ later in the interval.

The clock angle increase (from 140 to $170^{\circ}$ ) and $E_{\mathrm{KL}}$ enhancement (from 7.2 to $8.2 \mathrm{mV} \mathrm{m}^{-1}$ ) at 09:55-10:00 UT led to a convection increase at the dayside polar cap boundary at $\sim 11: 00 \mathrm{UT}$, as inferred from ground magnetometer data (Sandholt et al., 2014). This is consistent with a propagation delay from ACE of $65 \mathrm{~min}$. The same effect on dayside PC convection occurred at $\sim$ 07:00 UT, corresponding to the southward turning recorded by ACE at 06:00 UT (see Discussion). The latter event was accompanied by an abrupt $E_{\mathrm{KL}}$ increase from 8.5 to $10 \mathrm{mV} \mathrm{m}^{-1}$. The contributions from these magnetopause events (dayside source) to PC convection enhancements and associated $\mathrm{PCN}$-index increases can be estimated from the relation $\triangle \mathrm{PCN} / \mathrm{PCN}=\Delta E_{\mathrm{KL}} / E_{\mathrm{KL}}$. We find that these $\triangle \mathrm{PCN} /$ day events are minor in comparison to the $\triangle \mathrm{PCN} /$ night enhancements which are emphasized in this article.

\subsection{Magnetospheric data: GOES-Geotail-Cluster}

Figure 3 shows the position of three spacecraft (GOES10 , Geotail, and Cluster-1) in the geocentric solar magnetospheric (GSM) $X-Y$ and $X-Z$ planes during the central interval of our study: 06:00-12:00 UT. GOES-10 moved at geosynchronous altitude in the azimuthal direction from 21:00 MLT through midnight to 03:00 MLT. Geotail moved in the azimuthal direction on the dusk side, towards midnight $\left(Y_{\text {Geotail }}=10\right.$ to $2 R_{\mathrm{E}} ; X_{\text {Geotail }}=-11$ to $\left.-12 R_{\mathrm{E}}\right)$. Cluster-1 moved radially (inward) on the dawn side $\left(Y_{\text {Cluster }}=-5\right.$ to $-6 R_{\mathrm{E}} ; X_{\text {Cluster-1 }}=-18$ to $-15 R_{\mathrm{E}}$ ). GOES-10 was located in the Northern Hemisphere $\left(Z_{\mathrm{GOES}-10}=1-2 R_{\mathrm{E}}\right)$. Geotail and Cluster-1, respectively, were located in the Southern Hemisphere lobe/plasma sheet and the plasma sheet/lobe $\left(Z_{\text {Geotail }}=-5\right.$ to $-3 R_{\mathrm{E}} ; Z_{\text {Cluster-1 }}=-4$ to $\left.-7 R_{\mathrm{E}}\right)$.

Figure 4 shows GOES-10 data during the interval 06:0015:00 UT, when GOES moved from 21:00 MLT through midnight to dawn (06:00 MLT). We shall distinguish between two different event categories observed in sub-intervals I (06:00-12:00 UT; 21:00-03:00 MLT sector) and II (12:3015:00 UT; 03:30-06:00 MLT sector). Clear magnetic field dipolarizations at 06:25, 08:45, and 10:55 UT are marked by vertical guidelines. These events are characterized by abrupt (i) field magnitude decrease, (ii) $B_{x}$ decrease, and (iii) $B_{z}$ increase. Each of these events is preceded by intervals of field stretching ( $B$ increase, $B_{x}$ increase, $B_{z}$ decrease to $10-20 \mathrm{nT}$ ) and energetic electron flux decreases: 06:10 06:25, 08:00-08:45, and 10:15-10:55 UT. During the largest
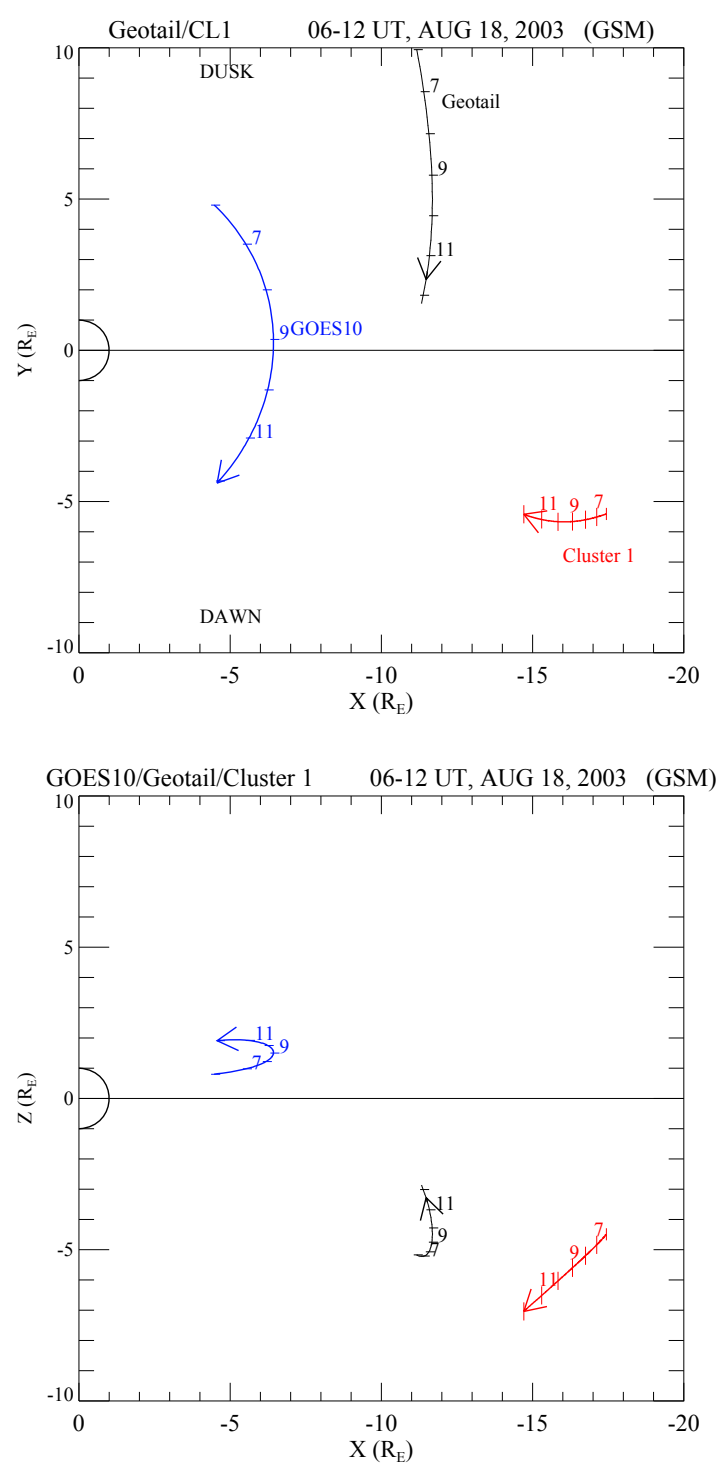

Figure 3. Tracks of three magnetospheric spacecraft in the GSM $X-Y$ (a) and $X-Z$ (b) planes during the interval 06:00-12:00 UT. GOES-10 moved from dusk to dawn at geosynchronous altitude. Geotail moved in the azimuthal direction on the dusk side towards the midnight sector $\left(Y_{\text {Geotail }}=10\right.$ to $2 R_{\mathrm{E}} ; X_{\text {Geotail }}=-11$ to $-12 R_{\mathrm{E}}$ ). Cluster 1 advanced earthward $\left(X_{\mathrm{Cluster}-1}=-18\right.$ to $\left.-15 R_{\mathrm{E}}\right)$ on the dawn side $\left(Y_{\text {Cluster }}=-5\right.$ to $\left.-6 R_{\mathrm{E}}\right)$. GOES-10 was located in the Northern Hemisphere $\left(Z_{\mathrm{GOES}-10}=1-2 R_{\mathrm{E}}\right)$. Geotail and Cluster-1, respectively, were located in the Southern Hemisphere lobe/plasma sheet and the plasma sheet/lobe $\left(Z_{\text {Geotail }}=-5\right.$ to $-3 R_{\mathrm{E}} ; Z_{\text {Cluster-1 }}=-4$ to $-7 R_{\mathrm{E}}$ ).

dipolarization event (08:45-09:00 UT), the $B_{z}$ component increased from 15 to $100 \mathrm{nT}\left(\Delta B_{z}=85 \mathrm{nT}\right)$ in $20 \mathrm{~min}$ (i.e. $\left.\Delta B_{z} / \Delta t=5.7 \mathrm{nT} \mathrm{min}{ }^{-1}\right)$ This was accompanied by $\Delta B=$ $-40 \mathrm{nT}$.

The current disruptions/dipolarizations events in interval I (06:00-12:00 UT; 21:00-03:00 MLT sector) are accompanied by energetic electron flux increases (see bottom panel). 

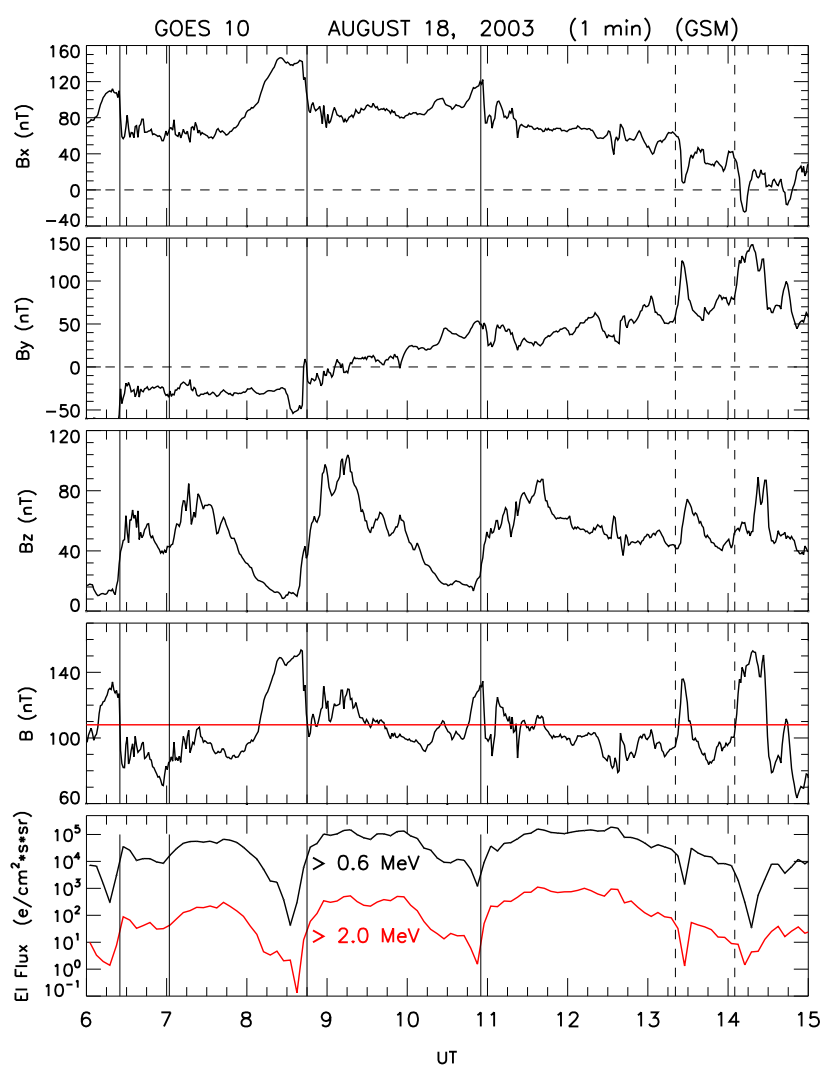

Figure 4. GOES-10 data obtained during the interval 06:0015:00 UT. From top to bottom the panels show $X, Y$, and $Z$ components of the magnetic field; the field magnitude; and the energetic differential electron fluxes in two energy regimes. Magnetic field dipolarizations $\left(\Delta B_{x}<0 ; \Delta B_{z}>0\right)$, current disruptions $(\Delta B<$ 0 ), and particle flux enhancements (sawtooth events) at 06:25, 08:45 and 10:55 UT are marked by vertical guidelines. A similar but weaker event (see particle fluxes) at 07:02 UT is also marked. The red line in the fourth panel gives the strength of the dipolar field. Magnetic field compression events at 13:20 and 14:05 UT are also marked.

This energetic particle behaviour is often referred to as sawtooth events (see e.g. Henderson et al., 2006).

The $B_{y}$ polarity shift from negative to positive at $\sim$ 09:00 UT marks when the satellite crosses from the dusk (premidnight) to the dawn (postmidnight) sector. After 12:30 UT (03:30 MLT: interval II) a different category of magnetic perturbation/particle flux events was recorded. This regime is characterized by magnetic field perturbation (field compression) events ( $B$ increase, $B_{x}$ decrease, $B_{y}$ increase, $B_{z}$ increase) accompanied by energetic particle decreases as detected during the intervals $13: 20-13: 35$ and 14:0514:30 UT.

Figure 5 shows a combination of Geotail and Cluster data during the interval 06:00-15:00 UT. Clear field dipolarizations at 07:02-07:25, 08:45-09:20, and 10:53-11:25 UT are detected by both spacecraft and are marked by dashed

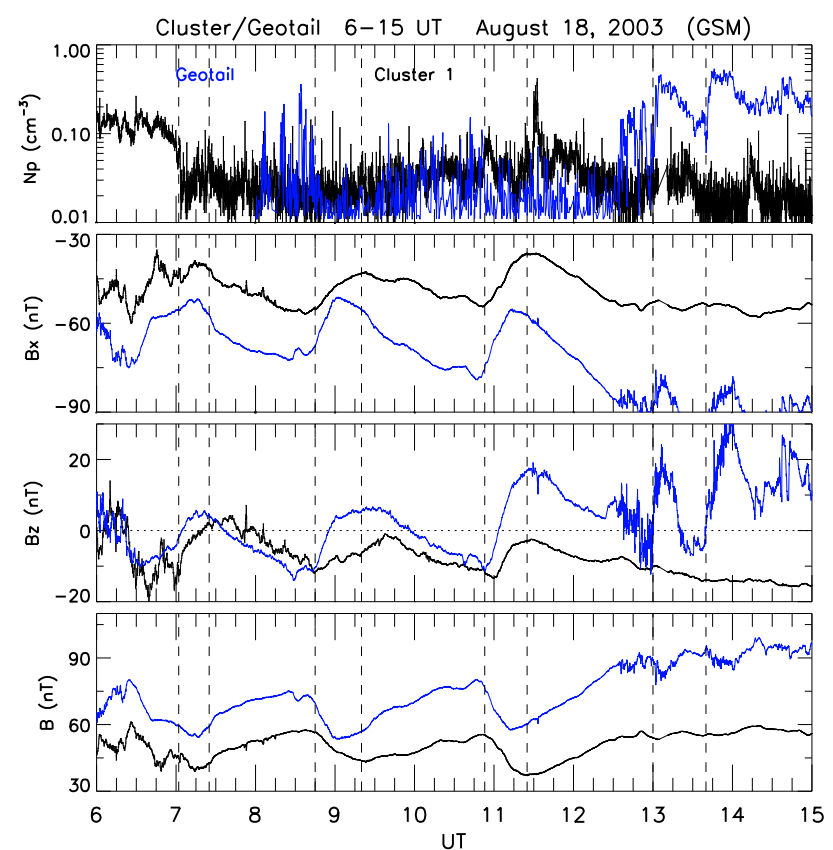

Figure 5. Geotail (blue traces) and Cluster-1 data during the interval 06:00-15:00 UT. Panels from top to bottom show plasma density and magnetic field components $B_{x}, B_{y}$, and $B_{z}$ in GSM coordinates, and the field magnitude. Intervals of field dipolarization at 07:02-07:25, 08:45-09:20, and 10:53-11:25 UT are marked by dashed vertical guidelines. Dipolarization fronts detected by Geotail (not Cluster) at 13:00 and 13:40 UT (blue traces) are also marked.

vertical guidelines. A different category of events is seen at Geotail at 13:00 and 13:40 UT but not at Cluster. The latter Geotail events (13:00/13:40 UT), appearing when Geotail entered the plasma sheet (see plasma density in top panel), are often referred to as dipolarization fronts (see e.g. Sitnov et al., 2009).

The dipolarization parameters $\Delta B, \Delta B_{x}$, and $\Delta B_{z}$ for the 09:00 and 11:00 UT events are as follows:

I. 09:00 UT: $\Delta B$ (GOES-10; $\left.X=-6.5 R_{\mathrm{E}}\right)=-40 \mathrm{nT}$; $\Delta B \quad\left(\right.$ Geotail; $\left.\quad X=-11.7 R_{\mathrm{E}}\right)=-17 \mathrm{nT} ; \quad \Delta B$ (Cluster-1; $X=-16.3 R_{\mathrm{E}}$ ) $=-13 \mathrm{nT} . \quad \Delta B_{x}$ (GOES$10)=-50 \mathrm{nT} ; \quad \Delta\left|B_{x}\right| \quad($ Geotail $)=-15 \mathrm{nT} ; \quad \Delta\left|B_{x}\right|$ $($ Cluster 1$)=-12 \mathrm{nT} . \Delta B_{z}(\mathrm{GOES}-10)=90 \mathrm{nT} ; \Delta B_{z}$ $($ Geotail $)=15 \mathrm{nT} ; \Delta B_{z}($ Cluster- 1$)=10 \mathrm{nT}$.

II. 11:00 UT: $\Delta B$ (GOES-10; $\left.X=-5.7 R_{\mathrm{E}}\right)=-30 \mathrm{nT}$; $\Delta B$ (Geotail; $\left.X=-11.6 R_{\mathrm{E}}\right)=-20 \mathrm{nT} ; \Delta B$ (Cluster $\left.1 ; \quad X=-15.3 R_{\mathrm{E}}\right)=-15 \mathrm{nT} . \quad \Delta B_{x} \quad($ GOES$10)=-30 \mathrm{nT} ; \quad \Delta\left|B_{x}\right| \quad($ Geotail $)=-23 \mathrm{nT} ; \quad \Delta\left|B_{x}\right|$ $\left(\right.$ Cluster-1) $=-18 \mathrm{nT} . \Delta B_{z}\left(\right.$ GOES-10) $=50 \mathrm{nT} ; \Delta B_{z}$ $($ Geotail $)=25 \mathrm{nT} ; \Delta B_{z}($ Cluster- 1$)=10 \mathrm{nT}$.

The data indicate a tailward propagation of the CD peak $\left(B_{\min }\right)$ during both the 09:00 and 11:00 UT events. The maximum of the CD events $\left(B_{\min }\right)$ is delayed at Cluster compared to Geotail. As a consequence of this evolution the 

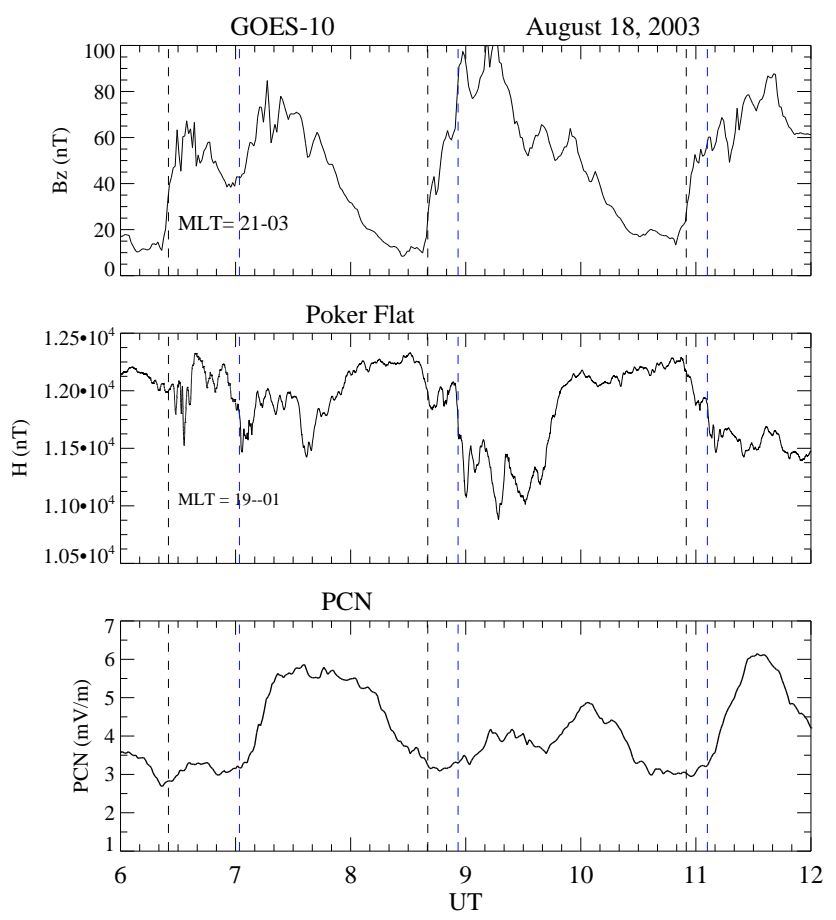

Figure 6. Panels from top to bottom show the GOES-10 $B_{z}$ component (nT), Poker Flat $H$-component deflection (nT), and the PCN index $\left(\mathrm{mV} \mathrm{m}^{-1}\right)$. Vertical dashed guidelines corresponding to pseudo-breakups (black) and major local onsets (blue) for each of the three sawtooth substorm are shown.

duration of the $\mathrm{CD}$ events maximizes at spacecraft Cluster1. At the Cluster location the negative $B$ gradient $(\mathrm{CD}$ event, marked by vertical guidelines in the figure) lasts approximately $30 \mathrm{~min}$ during the 09:00 and 11:00 UT events. From the perspective of estimating the spatial scale of the magnetic deflection events in the $X$ dimension, we find it to be of interest that the 09:00 and 11:00 UT perturbation events (the $\Delta B=-18.5 \mathrm{nT}$ vs. $-14 \mathrm{nT}$ ) are only marginally larger in the Geotail $\left(X=-11.6 R_{\mathrm{E}}\right)$ versus the Cluster $(X=$ $\left.-15.3 R_{\mathrm{E}}\right)$ data.

\subsection{Combined magnetosphere-ground data}

Figure 6 shows a combination of three parameters extracted from other figures: (i) the GOES $B_{z}$ component, (ii) Poker Flat $H$-component deflection, and (iii) the PCN index. Pseudo-breakups ( $t_{0}$, black) and major substorm onsets $\left(t_{1}\right.$, blue), as identified from Fig. 8 below, have been marked by dashed vertical guidelines. This data combination illustrates the association between GOES-10 $B_{z}$ events, auroral activity (WEJ intensifications), and the polar cap convection response ( $\mathrm{PCN})$ during the interval we study. We notice the major PCN increases following the onsets of major substorms at 07:02 and 11:00 UT. A similar effect, though less intense, is seen from 09:00 UT onwards. The persistent enhanced level of the PCN index during the intervals 07:20-

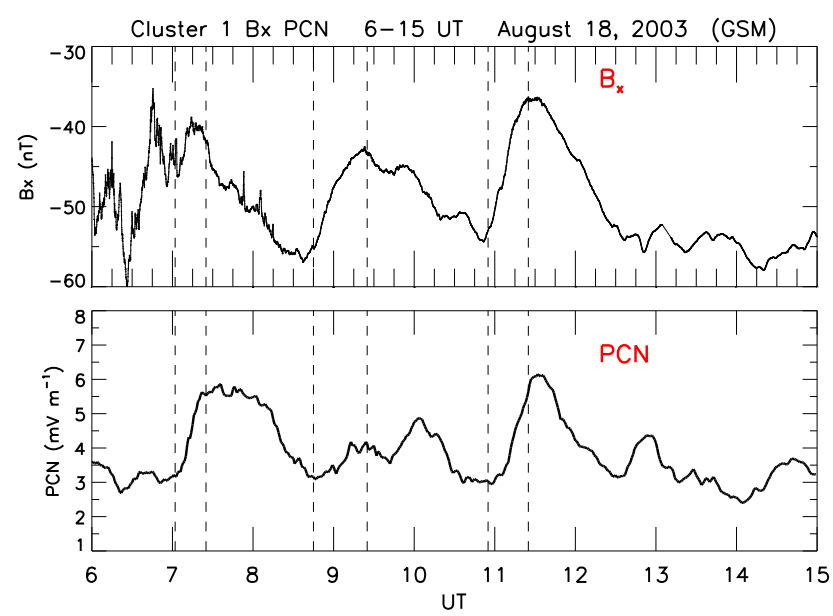

Figure 7. Cluster-1 magnetic field $B_{x}$ component trace (top, from Fig. 5) and the PCN index for the interval 06:00-15:00 UT. Three lobe magnetic field perturbation events are delimited by vertical guidelines.

08:15 and 09:10-10:20 UT are attributed to ongoing magnetotail reconnection. Decreasing PCN values (approaching the background, inter-event value of $\sim 3 \mathrm{mV} \mathrm{m}^{-1}$ ) are observed in intervals of magnetic field line stretching $\left(B_{z}<20 \mathrm{nT}\right)$ : 06:00-06:25, 08:15-08:40, and 10:20-10:55 UT. In these intervals the Poker Flat $H$ component and AL index (Paper 1) show a state of partial recovery.

Figure 7 shows a combination of Cluster-1 observation of the magnetic field $B_{x}$ component in the tail lobe and the PCN index representing polar cap convection (Troshichev et al., 2000; Kullen et al., 2010). Three dipolarization events $\left(\Delta\left|B_{x}\right|<0\right)$ reported above are delimited by vertical guidelines. Figure 7 demonstrates that each of these dipolarization events is accompanied by a monotonic rise of the PCN index by 1 to $3 \mathrm{mV} \mathrm{m}^{-1}$.

In our terminology the substorm evolution in this case may be subdivided into three phases: (i) an initial transient phase (e.g. 07:00-07:20 UT), (ii) a persistent phase (07:2008:10 UT), and (iii) the phase of partial recovery (08:10 $08: 45$ UT). The initial transient phase is characterized by dipolarization of the lobe field $\left(\left|B_{x}\right|\right.$ decrease) and monotonic rise of the PCN index $\left(\triangle \mathrm{PCN}=1-3 \mathrm{mV} \mathrm{m}^{-1}\right)$. The persistent phase is characterized by persistently high electrojet activity $(\mathrm{AL} \leq-800 \mathrm{nT})$, and a continuously high level of the $\mathrm{PCN}$ index $\left(\mathrm{PCN} \geq 4 \mathrm{mV} \mathrm{m}^{-1}\right)$. The phase of partial recovery is characterized by stretching of the lobe field, AL partial recovery ( $\mathrm{AL} \geq-800 \mathrm{nT})$, and $\mathrm{PCN}$ decrease approaching the background (dayside source) at $3 \mathrm{mV} \mathrm{m}^{-1}$. The $\mathrm{AL}$ index for this case is reported in Paper 1. 


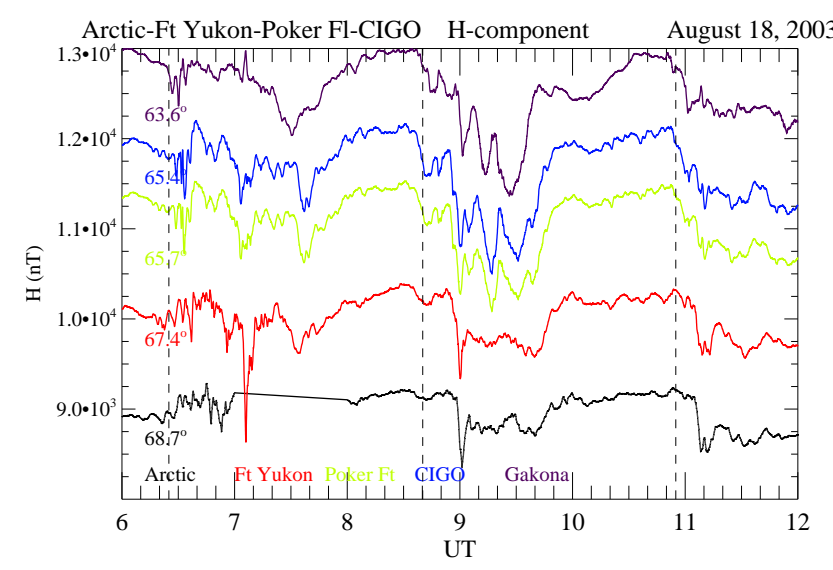

Figure 8. Alaska meridional chain magnetometer data ( $H$-component deflections) from stations Gakona (violet, 63.6 $6^{\circ}$ MLAT), CIGO (blue, $65.4^{\circ}$ MLAT), Poker Flat (green, 65. $7^{\circ}$ MLAT), Fort Yukon (red, 67.4 $4^{\circ}$ MLAT), and Arctic Village (black, 68.7 ${ }^{\circ}$ MLAT). Pseudo-breakups of the WEJ at 06:25, 08:40, and 10:55 UT are marked by vertical guidelines. Major onsets are identified at 07:02, 09:00, and 11:00 UT.

\subsection{Ground data across the auroral oval at midnight and postnoon MLTs}

Figure 8 shows magnetometer data from stations in the Alaska meridional chain: Gakona (violet, $63.6^{\circ} \mathrm{MLAT}$ ), CIGO (blue, $65.4^{\circ} \mathrm{MLAT}$ ), Poker Flat (green, $65.7^{\circ} \mathrm{MLAT}$ ), Fort Yukon (red, $67.4^{\circ}$ MLAT), and Arctic Village (black, 68. $7^{\circ}$ MLAT). Pseudo-breakups of the WEJ at 06:25, 08:40, and 10:55 UT are marked by dashed vertical guidelines. In contrast to the pseudo-breakups, the major onsets at 07:02, $\sim$ 09:00, and 11:00 UT are characterized by rapid poleward expansion of an intense WEJ (500-1000 nT $H$ deflection) up to Fort Yukon and Arctic Village (68.7 ${ }^{\circ}$ MLAT) within 2$3 \mathrm{~min}$ after the onset. This rapid expansion is followed by a long sequence of WEJ intensifications. The pattern of prolonged WEJ activity is particularly clear during the 09:0009:40 and 11:00-12:00 UT events. At this time (09:0012:00 UT) the chain of Alaska stations moved through the $\sim$ 22:00-01:00 MLT sector.

Figure 9 shows $X$-component magnetograms from stations in the IMAGE chain (Svalbard-Scandinavia-Finland region) spanning the latitude range from the polar cap (NAL at $75.4^{\circ}$ MLAT) via the auroral oval (SOR and OUJ at 66.3 and $61.0^{\circ} \mathrm{MLAT}$ ) to subauroral latitudes (TAR at $54.5^{\circ} \mathrm{MLAT}$ ). The negative $X$ deflection at NAL corresponds to enhanced antisunward convection in the polar cap. Positive deflections at lower latitudes within the interval 11:17-11:45 UT correspond to the enhanced EEJ current (sunward return flow) in the postnoon sector of the auroral oval. The time of 11:00 UT corresponds to $\sim$ 14:00-15:00 MLT along the IMAGE chain. This is an MLT sector where the impact from both the dayside and nightside convection sources is clearly seen. The

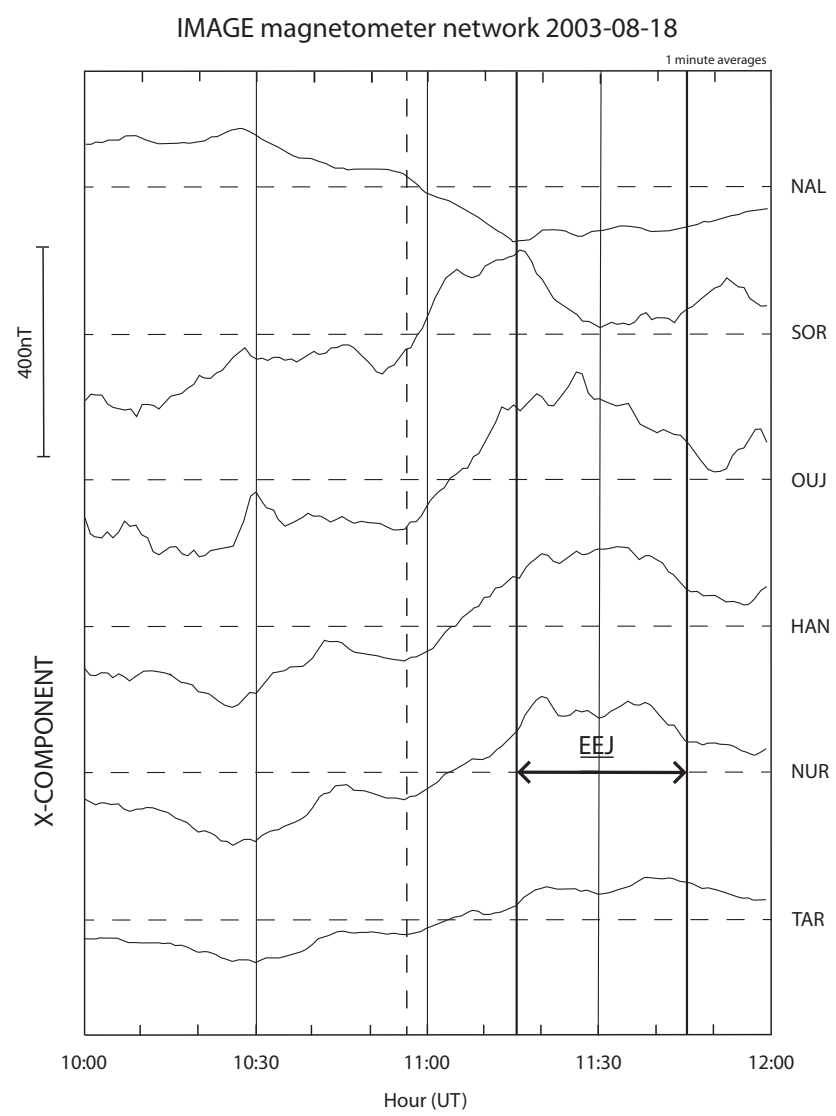

Figure 9. IMAGE chain magnetometer data ( $X$-component deflections) from stations NAL (75.4 $4^{\circ}$ MLAT), SOR (67.3 $3^{\circ}$ MLAT), OUJ (61. $0^{\circ}$ MLAT), HAN (58.7 ${ }^{\circ}$ MLAT), NUR (56.9 $9^{\circ}$ MLAT), and TAR $\left(54.5^{\circ} \mathrm{MLAT}\right)$. The interval of enhanced EEJ activity (11:1711:45 UT) at auroral oval south stations (HAN-NUR) is marked by vertical guidelines. The activity in the polar cap (NAL) and auroral oval north-expanded cleft (SOR) during the interval 10:5711:17 UT is attributed to the dayside convection source.

magnetic activity in the polar cap (NAL, $75.4^{\circ}$ MLAT) and in the auroral oval north regime (expanded cusp/cleft; see station SOR) in the interval 10:57-11:17 UT is attributed to the dayside convection source (see $E_{\mathrm{KL}}$ enhancement in Fig. 2). Thus, these data nicely illustrate the ionospheric response to an abrupt enhancement of the magnetopause reconnection rate. The enhanced effect of the dayside convection source lasted $20 \mathrm{~min}$.

The EEJ activity (positive $X$ deflections) appearing at auroral oval south (and subauroral) stations OUJ $\left(61.0^{\circ} \mathrm{MLAT}\right)$, HAN $\left(58.7^{\circ} \mathrm{MLAT}\right)$, and NUR (56. $9^{\circ}$ MLAT) in the interval 11:17-11:45 UT is attributed to the nightside source in the form of activation/expansion of the Bostrøm type II current loop on the dusk side (see Fig. 1). The electric field associated with the northward-directed ionospheric Pedersen current closure gives rise to the EEJ current. 
The combined data sets from Alaska and IMAGE (Svalbard-Scandinavia-Finland region) indicate the wide MLT-MLAT ranges of the impact of the present substorm activity, including enhanced WEJ near midnight, increased EEJ activity expanding into the postnoon sector, and polar cap convection enhancement monitored by the PCN index.

\section{Discussion}

\subsection{Substorms: the combined magnetosphere-ionosphere perspectives}

The ultimate goal of this type of study is to obtain an integrated view of the temporal evolution of the different channels of M-I coupling operating during substorm activity (see Fig. 1). The central issue is the spatial-temporal evolution of PS-magnetotail dynamics involving such features as (i) nearEarth CD (dipolarization), (ii) reconnection of tail lobe magnetic flux, and (iii) excitation of PC convection. In particular, the role played by nightside reconnection in driving polar cap convection has been uncertain. Thus, according to Gordeev et al. (2011), "a direct quantitative evaluation of the efficiency of the nightside reconnection in contributing to the polar cap potential still awaits to be done". We addressed this problem through our specific method of combining ground and satellite observations. Thus, our approach consists of a combination of the magnetospheric and ionospheric perspectives on the substorm activity. The main focus here is on M-I coupling during the variant of substorm activity appearing during interval I (06:00-12:30 UT) on 18 August 2003. This is a repetitive substorm activity driven by an ICME. In Paper 1 we documented central aspects of M-I coupling, with emphasis placed on a later interval II (13:00-17:00 UT) on this day.

The magnetospheric perspective consists of magnetic field and plasma data obtained from the magnetospheric spacecraft GOES-10, Geotail, and Cluster-1 during consecutive current disruption and magnetic field dipolarizations in the near-Earth PS and tail lobe system. This is a case of sawtooth substorms, i.e. strong substorms recurring at 2-3 h intervals (see e.g. Henderson et al., 2006). In this interval GOES-10 moved azimuthally from dusk to predawn (21:00-03:30 MLT) MLTs at geostationary altitude ( $X_{\mathrm{GOES}-10}$ within -5 to $-6 R_{\mathrm{E}} ; Y_{\mathrm{GOES}-10}=5$ to $-4 R_{\mathrm{E}}$ ). Geotail moved azimuthally from dusk to midnight $\left(Y_{\mathrm{GT}}=10\right.$ to $\left.2 R_{\mathrm{E}}\right)$ at $X_{\mathrm{GT}}=-11$ to $-12 R_{\mathrm{E}}$. Cluster moved inward $\left(X_{\mathrm{Cluster}}=-18\right.$ to $\left.-14 R_{\mathrm{E}}\right)$ on the dawn side $\left(Y_{\text {Cluster }} \sim\right.$ $\left.-6 R_{\mathrm{E}}\right)$.

Using this observation geometry we were able to address the question of temporal-spatial evolution of the magnetospheric magnetic perturbations initiated by near-Earth current disruption and magnetic field dipolarizations spanning the 21:00 to 03:00 MLT azimuthal sector. Thus, by combining the observations from GOES, Geotail, and Cluster we document the detailed evolution of these events in the nearEarth PS ( $X=-5$ to $-6 R_{\mathrm{E}} ; Z=1-2 R_{\mathrm{E}}$ ) and the tail lobes ( $X=-11$ to $-17 R_{\mathrm{E}} ; Z=-4$ to $-6 R_{\mathrm{E}}$ ). We shall then make estimates of the scale sizes $L_{x}$ and $L_{y}$ of the field dipolarization process.

These observations are discussed in the context of $\mathrm{M}-$ I coupling. The ionospheric perspective consists of auroral electrojet activations obtained from magnetometer chains in Alaska and Scandinavia-Finland (IMAGE chain), the AL index, and polar cap convection enhancements derived from the PCN index.

We address the long-standing question of the roles of inductive versus potential electric fields in $\mathrm{M}-\mathrm{I}$ coupling during substorms. Concerning the inductive electric fields we infer from the magnetic field dipolarizations, we distinguish between the near-Earth PS events ( $E_{\mathrm{PS}}$ derived from GOES data: $\left.\delta B_{z} / \delta t\right)$ and the tail lobe events $\left(E_{\mathrm{TL}}\right.$ derived from Geotail-Cluster data). The former ( $E_{\mathrm{PS}}$ originating in current disruption in the near-Earth PS) drives the westward electrojet centred at midnight $(\mathrm{SCW})$, while the latter $\left(E_{\mathrm{TL}}\right.$ originating in magnetotail reconnection) drives polar cap convection (PCN index). In our sawtooth substorms, both phenomena (near-Earth current disruption and magnetotail reconnection) are strongly related in the meaning that one leads to the other. Thus we suggest the following scenario of magnetospheric processes: (i) near-Earth current disruption leading to activation of the SCW with its "inner and outer loops" (see Sergeev et al., 2014), which is followed by (ii) activation of magnetic reconnection at the NENL (reconnection of lobe flux) with associated plasma injection. On the ionospheric level, this two-stage process is manifested as enhancements of (i) the auroral electrojets (via the Bostrøm type I and II systems) and (ii) the PCN index (see Fig. 1).

We distinguish between three stages of the evolution of the sawtooth substorms: (i) an initial transient phase characterized by a plasma sheet current disruption, an initial AL excursion followed by a monotonic PCN rise, (ii) a phase of persistent AL-PCN activity, and (iii) a phase of partial recovery which is initiated by a switch-off of magnetotail reconnection. The latter stage is characterized by stretching of the tail magnetic field, partial recovery of AL excursion, and PCN decrease towards a background level provided by the dayside convection source (magnetopause reconnection).

We point out the importance of combining the magnetospheric and ionospheric perspectives on the substorm expansion in order to obtain an integrated view of the evolution of the different $\mathrm{M}-\mathrm{I}$ coupling channels. In our case this can be exemplified by the third sawtooth substorm, where we identified the following essential phenomena: (i) nearEarth PS current disruption (SCW) at GOES-10 (10:5511:05 UT), (ii) WEJ major onset at 11:00 UT (Alaska chain at 24:00 MLT, Fig. 8), (iii) tail lobe magnetic perturbations (Geotail-Cluster) and polar cap convection enhancement (PCN rise) from 11:05 to 11:25 UT, (iv) EEJ enhancement (activation and expansion of the dusk-side branch of the 
Bostrøm type II system; see Fig. 1) reaching 15:00 MLT at 11:17 UT (IMAGE chain; Fig. 9), and (v) auroral electrojetand PCN decreases to the background level (cessation of reconnection of lobe flux) from 11:45 UT.

Figures 8 and 9 document the wide MLT range on the dusk side (15:00-24:00 MLT) of the impact of the substorm activity (eastward and westward electrojets), in addition to the polar cap convection enhancement, during the events we discuss here.

A simple illustration of the evolution of $\mathrm{M}-\mathrm{I}$ coupling in the interval of substorm expansion after the onset is given in Fig. 10. Cross-field tail currents (CTCs), FACs (R1), and WEJ currents in the ionosphere are essential elements in the M-I coupling representing the outer loop of the SCW. Radial $\left(L_{X}\right)$ and azimuthal $\left(L_{Y}\right)$ expansions of the $\mathrm{CD}$ (dipolarization) process correspond to poleward and east-west expansions of the aurora (and WEJ), respectively. The repeated expansions of the WEJ into the 17:00-18:00 MLT sector during the present case (18 August 2003) was documented in a recent ground-satellite DMSP F13 conjunction study (Paper 1).

We distinguish between inductive electric fields excited by field dipolarizations in the PS and tail lobes. As argued below, the tail lobe dipolarization process $\left(\boldsymbol{E}_{\mathrm{TL}} \propto \delta \boldsymbol{B} / \delta t\right)$ and its spatial scale in the dawn-dusk $(Y)$ direction, $L_{Y}$, contribute to the PC electric field $\left(\boldsymbol{E}_{\mathrm{PC}}\right)$ and to cross-polar-cap potential $(\mathrm{CPCP}) /$ night (i.e. $\left.E_{\mathrm{PC}} \cdot L_{\mathrm{PC}} \propto E_{\mathrm{TL}} \cdot L_{Y}\right) . L_{\mathrm{PC}}$ is the cross-polar cap (dawn-dusk) distance.

\subsection{Dipolarization events: spatial-temporal evolution and scale size estimates}

As described above we infer a two-source nature of the magnetic perturbations in the near-Earth PS and tail lobe system, i.e. near-Earth CDs and magnetotail reconnection. Thus, we expect that near-Earth CDs are the source of the GOES10 dipolarizations, while magnetotail reconnection may also contribute in the later phase of the Cluster-1 dipolarizations $\left(X \approx-16 R_{\mathrm{E}}\right)$, in intervals like 07:05-07:30 UT, 09:0509:20 UT, and 11:05-11:25 UT, when the PCN index shows a monotonic rise (see Fig. 7).

Our reasoning on the two-source nature of tail lobe magnetic perturbations (near-Earth PS current disruption versus magnetotail reconnection) is based on two independent sets of observations: (i) a major PCN-index rise which requires reconnection of lobe flux (see e.g. Lockwood et al., 2009) and (ii) data from the Wind satellite (not shown) in the tail $\left(X=-77 R_{\mathrm{E}}\right)$ showing reconnection signatures in the form of magnetic field reconfigurations (from $B_{x}$ dominated to $B_{z}$-dominated) and associated energetic particle flux enhancements during our events (07:00-09:0011:05 UT). These Wind observations may be explained in the context of magnetohydrodynamic (MHD) simulations reported by Sauvaud et al. (2012) (see their Fig. 13).

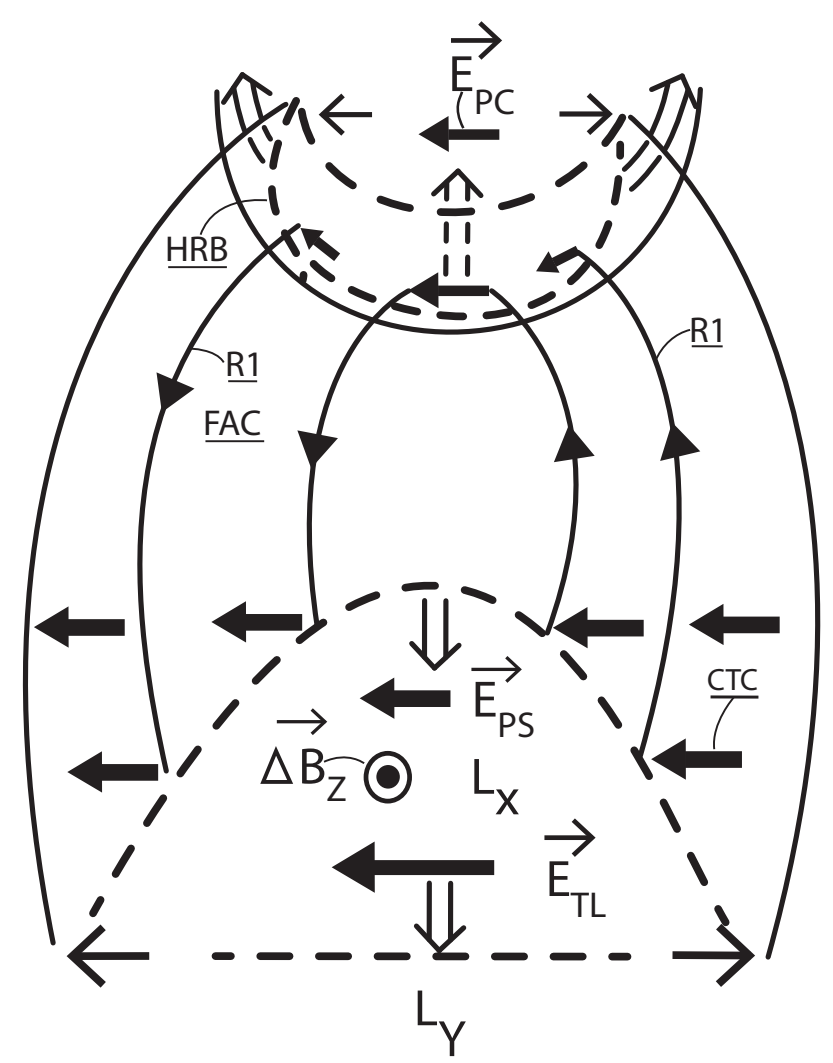

Figure 10. Schematic illustration of PS current disruption and associated auroral expansion after a major onset $\left(t_{1}\right)$. The geometry of a system of cross-tail currents (CTCs), FACs, and WEJ currents in the ionosphere are indicated at different times during the M-I coupling process. Electric fields in the PS ( $\left.\boldsymbol{E}_{\mathrm{PS}}\right)$ and tail lobes $\left(\boldsymbol{E}_{\mathrm{TL}}\right)$ related to the PS-tail-lobe magnetic field dipolarization $\left(\Delta B_{z} / \Delta t\right)$ processes, as well as the PC $\boldsymbol{E}$ field $\left(\boldsymbol{E}_{\mathrm{PC}}\right)$, have been marked. Spatial scales of the CD (dipolarization) process are marked $L_{X}$ and $L_{Y}$.

In the following we emphasize the dipolarizations of the sawtooth events initiated at 08:45 and 10:55 UT. Both these events show well-defined $\Delta B, \Delta B_{x}$, and $\Delta B_{z}$ signatures at all three spacecraft. The two dipolarizations at GOES10 are abrupt and have a large magnitude $(\Delta B=-40 \mathrm{nT}$; $\Delta B_{z}=50-80 \mathrm{nT} ; \Delta B_{x}=-50 \mathrm{nT}$ at 08:45 UT). The corresponding tail lobe deflections at Geotail and Cluster are easily identified, but they are smaller perturbations $(\triangle B=-15$ to $-20 \mathrm{nT} ; \Delta B_{x}=-10$ to $-20 \mathrm{nT} ; \Delta B_{z}=10$ to $25 \mathrm{nT}$ ) and evolve more gradually over $15-30 \mathrm{~min}$ long intervals. The dipolarization phase at Cluster $\left(X=-15\right.$ to $-16 R_{\mathrm{E}} ; Y=$ $-6 R_{\mathrm{E}}$ ) is longer (maximum reached later) than at Geotail $\left(X=-10\right.$ to $\left.-11 R_{\mathrm{E}} ; Y=3-9 R_{\mathrm{E}}\right)$. This observation is consistent with the two-source (CD and magnetotail reconnection) nature of the dipolarization process, as inferred above. 
Both the dipolarization and the preceding field line stretching are widely extended phenomena in the dawn-dusk direction. The events were observed by GOES-10 when it moved from evening (21:00 MLT) through midnight to pre-dawn (03:00 MLT). According to Lavraud and Borovsky (2008), a wide (cross-tail) regime of field stretching is expected during conditions of low Alfvén-Mach number in ICMEs. This is the condition of our case: $M_{\mathrm{A}}=3-4$.

Then we add that the 07:00 UT dipolarization event was also observed by Cluster $\left(X=-17 R_{\mathrm{E}}\right)$. From these observations we conclude that the scale sizes of the magnetic perturbation events in the $X$ and $Y$ dimensions are $L_{x} \approx 15 R_{\mathrm{E}}$ and $L_{y} \geq 15 R_{\mathrm{E}}$. Our azimuthal coverage on the dawn side is limited $\left(Y_{\text {Cluster-1 }} \geq-6 R_{\mathrm{E}}\right)$. The dusk-side observations of dipolarizations by Geotail extend to $Y=10 R_{\mathrm{E}}$. Thus, from symmetry considerations we shall use $L_{y}=20 R_{\mathrm{E}}$ for the azimuthal extent of the lobe magnetic perturbation.

$L_{x}$ is estimated to be $\sim 15 R_{\mathrm{E}}$, i.e. dipolarization covering the radial extent from the inside of GOES-10 to the outside of Cluster-1: $\sim-5$ to $-20 R_{\mathrm{E}}$. As support for the latter inference we note the similar, large $\Delta B$ and $\Delta B_{x}$ amplitudes recorded by Geotail $\left(X=-11.7 R_{\mathrm{E}}\right)$ and Cluster ( $X=-15.3 R_{\mathrm{E}}$ ) at 11:00 UT (see Fig. 5).

Related to this we note that Sergeev et al. (2014) recently presented a model of the SCW system, responsible for the field dipolarization, consisting of a two-loop system (one loop with R2 sense FAC connected to the partial ring current and the other with R1 sense FAC coupled to the near-Earth plasma sheet) located at radial distances between $X=-6$ and $-14 R_{\mathrm{E}}$. Sergeev et al. (2014) compared their model current system with a statistical study of dipolarization amplitudes $\left(\Delta B_{z}\right)$ observed at $X=-6.6$ and $-11 R_{\mathrm{E}}$. Our observations by GOES-10 and Geotail are comparable with their results. Specifically we note their $\sim 30 \mathrm{~min}$ long events of $\Delta B_{z} \approx 15 \mathrm{nT}$ at $X=-11 R_{\mathrm{E}}$, as detected by THEMIS probes. In our case Geotail $\left(X=-11 R_{\mathrm{E}} ; Y=\right.$ $3 R_{\mathrm{E}} ; Z=-4 R_{\mathrm{E}}$ ) observed 15 and $30 \mathrm{~min}$ long events with $\Delta B_{z}$ amplitudes of $\approx 15$ and $25 \mathrm{nT}$ at 09:00 and 11:00 UT, respectively. Our Cluster-1 $\left(X=-15.3 R_{\mathrm{E}} ; Y=-5 R_{\mathrm{E}} ; Z=\right.$ $-7 R_{\mathrm{E}}$ ) event at 11:00 UT shows a $30 \mathrm{~min}$ long $B_{z}$ increase of $10 \mathrm{nT}$.

Our reported observations of field dipolarizations from the GOES-10-Geotail-Cluster-1 constellation in the nearEarth PS and tail lobes will then be discussed in relation to the results of the previous studies by Sergeev et al. (2011) and Sauvaud et al. (2012). In their multi-spacecraft studies, both Sauvaud et al. (2012) and Sergeev et al. (2011) documented the large-scale nature of magnetospheric magnetic perturbations during substorms. Sergeev et al. (2011) studied small $(\mathrm{AE} \leq 500 \mathrm{nT})$, isolated substorms using a similar satellite constellation (GOES-Geotail-Cluster) to what we are using. Geotail was moving azimuthally at $X=-12 R_{\mathrm{E}}$. Cluster moved radially ( $X$ within -6 to $-18 R_{\mathrm{E}}$ ) and spent most of the time in the lobes. They point out that the lack of coverage in the azimuthal direction did not allow them to determine the longitudinal extent of the disturbance from the space data. They note that some of the substorm dipolarizations were not detected at GOES-17 and Geotail when the $Y$ coordinates of these spacecraft were 5 to $6 R_{\mathrm{E}}$. This indicates a limit on the longitudinal scales of these magnetic perturbation events: $L_{Y} \leq 8 R_{\mathrm{E}}$. The $B_{z}$ perturbations of their events at geostationary altitude and in the tail lobe at $X=-12 R_{\mathrm{E}}$ (Geotail) are given by $\Delta B_{z} / \Delta t$ (geostationary) $\sim 15 \mathrm{nT} / 10 \mathrm{~min}$ and $\Delta B_{z} / \Delta t$ (lobe) $\sim(5-10) \mathrm{nT} / 15 \mathrm{~min}$, respectively. These values are significantly lower than values for our repetitive, strong substorms ( $\mathrm{AL} \leq-1000 \mathrm{nT})$.

Sauvaud et al. (2012) found that dipolarization is a common feature of the geomagnetic tail, observed at $10-18 R_{\mathrm{E}}$ from the Earth, in the nightside plasma sheet and lobe during conditions similar to ours, i.e. repetitive substorms during storm time. These events are related to substorm onsets and propagate tailward from the $10-12 R_{\mathrm{E}}$ regime at velocities of $100-600 \mathrm{~km} \mathrm{~s}^{-1}$. They measured magnetic perturbations in the tail lobe (Cluster data at $X=-18 R_{\mathrm{E}}$ ). In these cases they observed dipolarization parameters $\Delta B_{z} / \Delta t$ (lobe) $\sim$ $10 \mathrm{nT} / 10 \mathrm{~min}$ and $\Delta\left|B_{x}\right| / \Delta t$ (lobe) $\sim-10 \mathrm{nT} / 10 \mathrm{~min}$. The latter values are similar to our observations in the tail lobes. But our events are initiated by current disruptions closer to Earth, near geostationary heights. This is inferred from the steep, strong B gradients measured by GOES-10 (Fig. 4). In the tail lobes at $X=-11$ (Geotail) to $-18 R_{\mathrm{E}}$ (Cluster-1), our events, initiated by abrupt dipolarizations at geostationary altitude (GOES-10), evolve into 15-25 min long dipolarization events before the new field-stretching phase sets in.

Sauvaud et al. (2012) found that the lobe magnetic field perturbations coincided with increases of the lobe electric field of $\sim 2.5 \mathrm{mV} \mathrm{m}^{-1}$. The measured electric field values were found to be consistent with an inductive electric field source $\left(E_{\text {ind }} \propto \delta \boldsymbol{B} / \mathrm{d} t\right)$. According to Sauvaud et al. (2012) "the lobe magnetic field changes appear to be the signature of a tailward retreating neutral line, with its associated current disruption/reduction." This interpretation is consistent with our observations.

\subsection{Inductive electric fields and polar cap convection}

The estimated large value of the inductive electric field in the plasma sheet in the early $(\sim 5-10 \mathrm{~min})$ stage of the major sawtooth expansion $\left(E_{\mathrm{PS}}=\left(\Delta B_{z} / \Delta t\right) \cdot L_{X} \approx 5 \mathrm{mV} \mathrm{m}^{-1}\right)$ is attributed to the rapid tailward $\left(L_{X}\right)$ and longitudinal $\left(L_{Y}\right)$ expansions of the field dipolarization process $\left(\Delta B_{z} / \Delta t \approx\right.$ $\left.50 \mathrm{nT} / 10 \mathrm{~min} \approx 10^{-10} \mathrm{~V} \mathrm{~m}^{-2}\right)$. These are reflected in the auroral electrojet (see Fig. 8 and AL index in Paper 1). Relevant to us here is also the dawn-dusk electric potential in the tail lobes which can be transferred along open field lines to the polar cap and give rise to polar cap convection and corresponding PCN increases.

Based on our estimates of the spatial $\left(L_{X} \sim 15 R_{\mathrm{E}} ; L_{Y} \sim\right.$ $\left.20 R_{\mathrm{E}}\right)$ and temporal $(15-30 \mathrm{~min})$ scales of the tail lobe magnetic perturbations, we can then make estimates of the 
cross-tail potential generated during the evolution of dipolarization process in the tail lobes. This parameter is particularly important since it can be a source of polar cap potential enhancements during the initial transient phase of substorm expansions (marked by vertical guidelines in Fig. 7).

An estimate of the cross-tail potential (CTP) can be derived as follows: $\mathrm{CTP}=E_{\mathrm{CT}} \cdot L_{Y} \approx E_{\mathrm{TL}} \cdot L_{Y}$, where $E_{\mathrm{TL}}=$ $\left(\Delta B_{x} / \Delta t\right) \cdot L_{z}$.

This expression for $E_{\mathrm{TL}}$ is based on Faraday's law for the case of an $E_{Y}$-dominated electric field component and small gradients in the $y$ direction $(\delta / \delta y \approx 0)$ in the system of plasma sheet tail lobes: $\delta E_{Y} / \delta x=-\delta B_{z} / \delta t ; \delta E_{Y} / \delta z=$ $\delta B_{x} / \delta t$. Then we obtain the relations we shall apply in this study: $\Delta E_{Y} \approx-\left(\Delta B_{z} / \Delta t\right) \cdot L_{X}$ and $\Delta E_{Y} \approx\left(\Delta B_{X} / \Delta t\right) \cdot L_{Z}$, where $L_{X}$ and $L_{Z}$ are characteristic scale lengths of the magnetic perturbations in the $X$ and $Z$ dimensions $\left(\Delta B_{z} / \Delta x=\right.$ $\left.B_{z} / L_{x} ; \Delta B_{x} / \Delta z=B_{x} / L_{z}\right)$.

In our case $\Delta B_{z} / \Delta t$ (TL) $\sim 15 \mathrm{nT} / 15 \mathrm{~min}$ (see Geotail data). Then we apply the derived estimates of the spatial scales of the magnetic perturbations in the tail lobes during the documented dipolarization events: $L_{X}=15 R_{\mathrm{E}} ; L_{y}=$ $20 R_{\mathrm{E}} ; L_{z}=25 R_{\mathrm{E}}$. The latter value $\left(L_{z}=25 R_{\mathrm{E}}\right)$ is taken from Sauvaud et al. (2012). This gives $E_{\mathrm{TL}} \sim 2.5 \mathrm{mV} \mathrm{m}^{-1}$. $\Delta \mathrm{CTP}=2.5 \mathrm{mV} \mathrm{m}^{-1} \times 20 R_{\mathrm{E}}=320 \mathrm{kV}$.

An estimate of the polar cap potential can be obtained when we use the M-I potential transmission factor derived by Gordeev et al. (2011): $\triangle \mathrm{CPCP}=(0.1-0.2) \cdot \triangle \mathrm{CTP}$. Then we have $\triangle \mathrm{CPCP}=(0.1-0.2) \cdot \Delta \mathrm{CTP} \approx 30-60 \mathrm{kV}$. Due to the lack of spacecraft coverage beyond $Y_{\mathrm{GSM}}=10 R_{\mathrm{E}}$, the inferred CPCP values are lower limits. Thus, for the first time, we establish lower limits on the contribution to the CPCP from inductive electric field coupling between the tail lobes and the polar cap ionosphere.

At this stage we take advantage of the following expression for the empirical relation between CPCP enhancements and PCN increases during the category of events we study (Sandholt et al., 2012): $\triangle \mathrm{CPCP}(\mathrm{V}) \approx 5 \Delta \mathrm{PCN}$ $\left(\mathrm{mV} \mathrm{m}^{-1}\right) \cdot L_{\mathrm{PC}}(\mathrm{km}) . L_{\mathrm{PC}}$ is the cross-polar cap distance. In our case $L_{\mathrm{PC}} \sim 4500 \mathrm{~km}$ (see Paper 1 ). This gives $\Delta \mathrm{PCN}=(30-60) \mathrm{kV} /(5 \times 4500 \mathrm{~km})=(1.3-2.6) \mathrm{mV} \mathrm{m}^{-1}$.

This estimate fits well with the ground observations of polar cap convection enhancement (PCN rises of $1.5-3 \mathrm{mV} \mathrm{m}^{-1}$ ) in the initial transient phase of $\mathrm{M}-\mathrm{I}$ coupling in these substorm cases (see PCN index in Fig. 7).

\section{Summary and conclusions}

The repetitive storm-time substorm activity excited during the Earth passage of an ICME on 18 August 2003 may be divided in two different variants occurring in two subintervals: I (04:00-12:30 UT) and II (12:30-18:00 UT). As documented in Paper 1, the AL-PCN activity in interval I recurs at 2-2.5 $\mathrm{h}$ intervals, while the interval II activity consists of shorter AL-PCN events recurring at 20-50 min intervals.
The interval I substorm activity is accompanied by particle injections to geostationary altitude, which are often referred to as sawtooth events (Henderson et al., 2006). As discussed in Noah and Burke (2014), the two types of stormtime substorm activity may correspond to different conditions of magnetotail reconnection in the presence of strong ring current developments, i.e. sustained near-Earth neutral line (NENL) activity versus a state of more chaotic (sporadic) magnetotail merging. As described in more detail below, in this paper we extend the initial study (Paper 1) in different ways by addition of data sets referring to the magnetospheric and ionospheric levels which are relevant for shedding light on basic elements of M-I coupling prevailing during the sawtooth substorms observed in interval $\mathrm{I}$, when the ring current index SYM-H lies within -80 to $-100 \mathrm{nT}$.

Based on data from a fortuitous configuration of magnetospheric satellites, we have documented the spatial-temporal evolution of magnetic perturbations (dipolarizations) in the near-Earth plasma sheet (GOES-10) and in the tail lobes (Geotail and Cluster-1) during sawtooth substorms. The Geotail-Cluster configuration in the present case gives information about the large-scale nature of the tail lobe perturbations appearing during sawtooth substorms. In the interval, we study Geotail-Cluster-detected magnetic perturbations in a large sector of the tail lobes: $X_{\mathrm{GSM}}=-11$ to $-17 R_{\mathrm{E}} ; Y_{\mathrm{GSM}}=-6$ to $10 R_{\mathrm{E}}$. This represents an extension with respect to similar type of data published in previous work (see e.g. Sergeev et al., 2011; Sauvaud et al., 2012). The extended spacecraft coverage was applied to make reasonable estimates of CPCP enhancements from inductive electric field coupling between the tail lobes and the polar cap ionosphere.

Ground signatures of activations of the substorm current loops (see Fig. 1), as they appear in the westward electrojet around midnight and in the eastward electrojet at 14:00-15:00 MLT (see the 11:17-11:45 UT event), are documented by magnetograms from Alaska and the SvalbardScandinavia-Finland region, respectively. These ground data reflect the wide MLT-MLAT ranges of the impact of the present substorm activity (eastward and westward electrojets and polar cap convection). By combining the observations on the magnetosphere and ionosphere levels of the substorm activity, we can infer a scenario of M-I coupling events involving near-Earth current disruption and magnetotail reconnection, associated activations of substorm current loops (SCW), and their manifestations in auroral electrojets and electric field coupling to the polar cap ionosphere.

This paper serves as an extension of Paper 1, as indicated below. We place the activations of the SCW during the documented "sawtooth variant" (GOES-10 data at geostationary altitude) of substorm activity in the larger context of ionospheric and magnetotail dynamics, most notably tail lobe magnetic field perturbations obtained by Geotail $\left(X \sim-11 R_{\mathrm{E}}\right)$ and Cluster-1 $\left(X=-18\right.$ to $\left.-15 R_{\mathrm{E}}\right)$. Observations of the latter perturbations are essential for estimating 
the role that the induction electric field plays in the excitation of polar cap convection, as monitored by the PCN index. On this point we refer to the good correlation we found between the $B_{x}$ deflections of the tail lobe (Cluster-1) and the monotonic rise of the PCN index marked by vertical dashed guidelines in Fig. 7. Estimates of the dawn-dusk-directed tail lobe induction electric field $\left(E_{\mathrm{TL}} \sim\left(\Delta B_{x} / \Delta t\right) \cdot L_{z}\right)$, as well as its scale size in the $Y$ dimension $\left(L_{Y} \geq 20 R_{\mathrm{E}}\right)$, which are derived on the basis of the favourable configuration of Geotail and Cluster-1, were used to calculate the polar cap convection response during the initial substorm expansion phase. The contribution to the CPCP is estimated from the following relation: $\mathrm{CPCP}=(0.1-0.2) \cdot E_{\mathrm{TL}} \cdot L_{Y} \approx 30-60 \mathrm{kV}$. This corresponds to the observed 1.5 to $3 \mathrm{mV} \mathrm{m}^{-1}$ increases of the PCN index. Due to the lack of spacecraft coverage (GeotailCluster) beyond $Y_{\mathrm{GSM}}= \pm 10 R_{\mathrm{E}}$ the inferred CPCP values are lower limits.

The broader ionospheric context of the SCW documented in this paper is based on readings from the IMAGE chain magnetometer data in the postnoon sector (EEJ activity near 14:00-15:00 MLT) combined with Alaska chain data from the midnight sector (WEJ activity near 24:00 MLT). In this way we can monitor ionospheric signatures of the "inner" and "outer" loops of the SCW-PRC system. The "inner loop" consists of the PRC-EEJ (on the dusk side) connection via a Bostrøm type II system. The outer loop consists of the connection between the CTC (disruption of the cross-tail current) and the WEJ via a Bostrøm type I system (see Fig. 1). Thus, in our extended two loop model of the SCW we specify the connection between the standard "inner loop" (Sergeev et al., 2014) and the EEJ (dusk side) via a Bostrøm type II current system (our Fig. 1). This extension of the standard two-loop model of the SCW is essential in order to obtain a relevant description of $\mathrm{M}-\mathrm{I}$ coupling and the timescales of the system. By combining ground observations relating to ionospheric manifestations of both current loops (WEJ at 24:00 MLT and EEJ at 14:00-15:00 MLT) we are able to determine the characteristic time of activation/expansion of the complex substorm current system. In the case of the 11:00 UT event we note a 17 min delay between the major intensification of the WEJ (Alaska chain) at 11:00 UT (WEJ at 24:00 MLT, representing activation of the "outer loop") and the full expansion of the EEJ activation (IMAGE data) to 14:00-15:00 MLT (representing the "inner loop"). This $17 \mathrm{~min}$ interval corresponds to the injection of plasma (PS) from the "outer" to the "inner loop" and the associated braking and azimuthal deflection of the plasma at the PS-PRC boundary which constitutes a dynamo $(\boldsymbol{E} \cdot \boldsymbol{J}<0)$ for the Bostrøm type II system, as indicated schematically in Fig. 1.

The sawtooth substorm events are furthermore discussed in relation to magnetotail reconnection on the basis of Wind observations of reconnection signatures at $X=-77 R_{\mathrm{E}}$ (ion flux variations in relation to magnetic field configurations) and the polar cap index (PCN). This effort lead us to distinguish between the following three substorm stages: i. an initial transient phase dominated by

a. large-scale magnetic field dipolarization in the azimuthal (21:00-03:00 MLT) and radial dimensions of the PS (activation of inner and outer loops of SCW-EEJ/WEJ activity) and

b. tail lobe magnetic perturbations with associated inductive electric field coupling to the polar cap ionosphere (PCN monotonic rise);

ii. a persistent phase of PS field dipolarization(s) and corresponding electrojet (EEJ/WEJ)-PCN activity;

iii. a phase of PS and tail lobe magnetic field stretching, partial recovery of electrojet activity, and PCN decrease towards the background level (dayside source) after the cessation of magnetotail reconnection.

In summary, we emphasize two elements of our study: (i) a combination of M-I data sets is discussed within the framework of a two-loop model of the SCW/PRC-ionosphere connection applicable to the prevailing substorm activity where we identify "outer" and "inner loop" manifestations in the near-Earth plasma sheet (GOES data)-auroral oval/midnight (Alaska chain data) and in the oval south regime at 14:0015:00 MLT (IMAGE chain data), respectively, and (ii) observations of inductive electric field coupling between the magnetotail lobes (Geotail-Cluster data) and the polar cap ionosphere (PCN index), i.e. excitation of PC convection, leading us to make a qualified estimate of its contribution to the cross-polar cap potential.

Acknowledgements. We thank the Geophysical Institute, University of Alaska, Fairbanks, for access to geomagnetic data obtained from the Alaska meridian chain of magnetometers. We thank the institutions who maintain the IMAGE array of magnetometers (FMI, Finland, and Geophysical Observatory, Troms $\varnothing$, Norway). IMAGE data used in this study were obtained from www.geo.fmi.fi/image. Work supported in part by NASA grants NNX10AQ29G and NNX13AP39G.

Topical Editor L. Blomberg thanks A. Kullen and the two anonymous referees for their help in evaluating this paper.

\section{References}

Aikio, A. T., Sergeev, V. A., Shukhtina, M. A., Vagina, L. I., Angelopoulos, V., and Rees, G. D.: Characteristics of pseudobreakups and substorms observed in the ionosphere, at geosynchronous orbit, and in the midtail, J. Geophys. Res., 104, 1226312287, doi:10.1029/1999JA900118, 1999.

Akasofu, S.-I.: The development of the auroral substorm, Planet. Space Sci., 12, 273-282, 1964.

Akasofu, S.-I.: The relationship between the magnetosphere and magnetospheric/auroral substorms, Ann. Geophys., 31, 387-394, doi:10.5194/angeo-31-387-2013, 2013. 
Birn, J. and Hesse, M.: The substorm current wedge in MHD simulations, J. Geophys. Res., 118, 3364-3376, doi:10.1002/jgra.50187, 2013.

Bostrøm, R.: A model of the auroral electrojets, J. Geophys. Res., 69, 4983-4999, 1964.

Bostrøm, R.: Currents in the ionosphere and magnetosphere, in: The Birkeland Symposium on Aurora and Magnetic Storms, edited by: Egeland, A. and Holtet, J., 445-458, C.N.R.S., Sandefjord, 1967.

Chen, C. X. and Wolf, R. A.: Interpretation of high-speed flows in the plasma sheet, J. Geophys. Res., 98, 21409-21419, 1993.

Cowley, S. W. H.: The role and location of magnetic reconnection in the geomagnetic tail during substorms, in: SUBSTORMS 1, ESA SP-335, 401-404, 1992.

Friedrich, E., Samson, J. C., Voronkov, I., and Rostoker, G.: Dynamics of the substorm expansive phase, J. Geophys. Res., 106, 13145-13163, 2001.

Gordeev, E. I., Sergeev, V., Pulkkinen, T. I., and Palmroth, M.: Contribution of magnetotail reconnection to the cross-polar cap electric potential drop, J. Geophys. Res., 116, A08219, doi:10.1029/2011JA016609, 2011.

Henderson, M. G., Skoug, R., Donovan, E., Thomsen, M. F., Reeves, G. D., Denton, M. H., Singer, H. J., McPherron, R. L., Mende, S., Immel, T. J., Sigwarth, J. B., and Frank, L. A.: Substorms during the 10-11 August 2000 sawtooth event, J. Geophys. Res., 111, A06206, doi:10.1029/2005JA011366, 2006.

Kan, J. R. and Lee, L. C.: Energy coupling function and solar windmagnetosphere dynamo, Geophys. Res. Lett., 6, 577-580, 1979.

Katus, R. M., Liemohn, M. W., Gallagher, D. L., Ridley, A., and Zou, S.: Evidence for potential and inductive convection during intense geomagnetic events using normalized superposed epoch analysis, J. Geophys. Res., 118, 181-191, doi:10.1029/2012JA017915, 2013.

Koskinen, H. E. J., Lopez, R. E., Pellinen, R., Pulkkinen, T. I., Baker, D. N., and Bøsinger, T.: Pseudobreakup and substorm growth phase in the ionosphere and magnetosphere, J. Geophys. Res., 98, 5801-5813, 1993.

Kozelova, T. V., Pudovkin, M. I., and Treilhou, J. P.: Development of the auroral bulge and dipolarization at $6.6 r_{\mathrm{E}}$, in: SUBSTORM 1, ESA SP-335, 1992.

Kullen, A., Ohtani, S., and Karlsson, T.: Geomagnetic signatures of auroral substorms preceded by pseudobreakups, J. Geophys. Res., 114, A04201, doi:10.1029/2008JA013712, 2009.

Kullen, A., Karlsson, T., Cumnock, J. A., and Sundberg, T.: Occurrence and properties of substorms associated with pseudobreakups, J. Geophys. Res., 115, A12310, doi:10.1029/2010JA015866, 2010.

Lavraud, B. and Borovsky, J. E.: Altered solar wind-magnetosphere interaction at low Mach numbers: Coronal mass ejections, J. Geophys. Res., 113, A00B08, doi:10.1029/2008JA013192, 2008.

Lockwood, M., Hairston, M., Finch, I., and Roillard, A.: Transpolar voltage and polar cap flux during the substorm cycle, J. Geophys. Res., 114, A0120, doi:10.1029/2008JA013697, 2009.

Lopez, R. E. and Freeman, J. W.: Solar wind proton temperaturevelocity relationship, J. Geophys. Res., 91, 1701-1705, 1986.

Lui, A. T. Y.: A synthesis of magnetospheric substorm models, J. Geophys. Res., 96, 1849-1856, doi:10.1029/90JA02430, 1991.
Lui, A. T. Y.: Auroral activity associated with fast plasma flows in the magnetotail, Geophys. Res. Lett., 27, 3245-3248, 2000.

Lui, A. T. Y. and Murphree, J. S.: A substorm with onset tied to an auroral arc, Geophys. Res. Lett., 25, 1269-1272, doi:10.1029/98GL00758, 1998.

McPherron, R. L., Russell, C. T., and Aubry, M. A.: Satellite studies of magnetospheric substorms on August 15, 1968, 9, phenomenological model for substorms, J. Geophys. Res., 78, 31313149, 1973.

Nakamura, R., Baker, D. N., Belian, R. D., and Yamamoto, T.: Spatial scale of the substorm onset region determined from multipoint satellite and ground-based observations, in: SUBSTORMS 1, ESA SP-335, 353-357, 1992.

Nakamura, R., Baker, D. N., Yamamoto, T., Belian, R. D., Bering III, E. A., Benbrook, J. R., and Theall, J. R.: Particle and field signatures during pseudobreakup and major expansion onset, J. Geophys. Res., 99, 207-221, doi:10.1029/93JA02207, 1994.

Nielsen, E. and Greenwald, R. A.: Electron flow and visual aurora at the Harang discontinuity, J. Geophys. Res., 84, 4189-4200, 1979.

Noah, M. A. and Burke, W. J.: Magnetospheric conditions for sawtooth event development, J. Geophys. Res., 119, 2494-2511, doi:10.1002/2013JA019573, 2014.

Pulkkinen, T. I., Baker, D. N., Wiltberger, M., Goodrich, C., Lopez, R. E., and Lyon, J. G.: Pseudobreakup and substorm onset: Observations and MHD simulations compared, J. Geophys. Res., 103, 14847-14854, 1998.

Pulkkinen, T. I., Partamies, N., McPherron, R. L., Henderson, M., Reeves, G. D., Thomsen, M. F., and Singer, H. J.: Comparative statistical analysis of storm time activations sawtooth events, J. Geophys. Res., 112, A01205, doi:10.1029/2006JA012024, 2007.

Richardson, I. G. and Cane, H. V.: Near-Earth interplanetary coronal mass ejections during solar cycle 23 (1996-2009): Catalog and summary of properties, Sol. Phys., 264, 189-237, 2010.

Sandholt, P. E., Andalsvik, Y. L., and Farrugia, C. J.: The pulsed nature of the nightside contribution to polar cap convection: repetitive substorm activity under steady interplanetary driving, Ann. Geophys., 30, 1539-1553, doi:10.5194/angeo-30-15392012, 2012.

Sandholt, P. E., Farrugia, C. J., and Denig, W. F.: M-I coupling across the auroral oval at dusk and midnight: repetitive substorm activity driven by interplanetary coronal mass ejections (CMEs), Ann. Geophys., 32, 333-351, doi:10.5194/angeo-32-333-2014, 2014.

Sauvaud, J.-A., Jacquey, C., Oka, M., Palin, L., Fruit, G., Kistler, L. M., Balough, A., Cao, J. B., Reeves, G., Mukai, T., Shinohara, I., and Grigorenko, E.: A study of the near-Earth plasma sheet and lobe driven by multiple substorms: Comparisons with a full particle simulation of reconnection, J. Geophys. Res., 117, AO1221, doi:10.1029/2011JA017033, 2012.

Sergeev, V. A., Liou, K., Newell, P. T., Ohtani, S.-I., Hairston, M. R., and Rich, F.: Auroral streamers: characteristics of associated precipitation,convection and field-aligned currents, Ann. Geophys., 22, 537-548, doi:10.5194/angeo-22-537-2004, 2004.

Sergeev, V. A., Tsyganenko, N. A., Smirnov, M. V., Nikolaev, A. V., Singer, H. J., and Baumjohann, W.: Magnetic effects of the substorm current wedge in a "spread-out-wire" model and their com- 
parison with ground, geosynchronous, and tail lobe data, J. Geophys. Res., 116, A07218, doi:10.1029/2011JA016471, 2011.

Sergeev, V. A., Angelopoulos, V., and Nakamura, R.: Recent advances in understanding substorm dynamics, Geophys. Res. Lett., 39, L0511, doi:10.1029/2012GL050859, 2012.

Sergeev, V. A., Nikolaev, A. V., Tsyganenko, N. A., Angelopoulos, V., Runov, A. V., Singer, H. J., and Yang, J.: Testing a two-loop pattern of the substorm current wedge, J. Geophys. Res., 119, 947-963, doi:10.1002/2013JA019629, 2014.

Sitnov, M. I., Swisdak, M., and Divin, A. V.: Dipolarization fronts as a signature of transient reconnection in the magnetotail, J. Geophys. Res., 114, A04202, doi:10.1029/2008JA013980, 2009.
Troshichev, O. and Janzhura, A.: Relationship between the PC and $\mathrm{AL}$ indices during repetitive bay-like magnetic disturbances in the auroral zone, J. Atmos. Sol.-Terr. Phy., 71, 1340-1352, 2009.

Troshichev, O. A., Lukianova, R. Y., Papitashvili, V. O., Rich, F. J., and Rasmussen, O.: Polar cap index (PC) as a proxy for ionospheric electric field in the near-pole region, Geophys. Res. Lett., 27, 3809-3812, doi:10.1029/2000GL003756, 2000. 